\title{
The Studies of Small Space Vehicles Ammoniac Electrothermal Engine Units Design and Structural Layout
}

\author{
Viktor Nikolaevich Blinov ${ }^{1}$, Igor Sergeevich Vavilov ${ }^{1}$, Valeriy Vladimirovich Kositsin ${ }^{1}$, Viktor Ivanovich \\ Ruban $^{1}$, Elena Viktorovna Khodoreva ${ }^{1} \&$ Viktor Vladimirovich Shalay ${ }^{1}$ \\ ${ }^{1}$ Omsk State Technical University, Omsk, Russian Federation \\ Correspondence: Viktor Nikolaevich Blinov, Omsk State Technical University, Omsk, Russian Federation. \\ E-mail: blinovwiktor@yandex.ru
}

Received: February 15, 2015

Accepted: March 15, 2015

Online Published: April 16, 2015

doi:10.5539/mas.v9n5p337

URL: http://dx.doi.org/10.5539/mas.v9n5p337

The paper represents results of works carried out in the context of Grants Agreement No. 14.574.21.0104 as of 08.09.2014 concluded with the Ministry of Education and Science of the Russian Federation and related to applied researches. The paper is written with the support of leading scientific school HW-5998.2014.10.

\begin{abstract}
The paper studies the issues of design and structural layout of ammoniac corrective engine units (CEU) with electrothermal micromotors (ETMM) for manoeuvrable small space vehicles (SSV) using all-purpose approach. CEU and ETMM structural schemes are defined, adaptation questions of CEU to SSV are addressed, CEU mass analysis is carried out, and experimental study's findings are given.
\end{abstract}

Keywords: ammonia, corrective engine unit, small space vehicles, manoeuvring, electrothermal micromotor

\section{Introduction}

The modern stage of cosmic space exploration is characterized by large-scale development and use of SSV of 30-400 kg for solving scientific and application problems launched by group and additional ways (Sadovnichy e.t al., 2011; Sadovnichy et al, 2007; Blinov et al., 2010; Blinov et al., 2010; Blinov et al., 2010). For that reason, there are relevant objectives of SSV orbital manoeuvring: liquidation of orbital injection mistakes, orbital parameters maintenance during the period of active existence, inter-orbital manoeuvring, SSV orbital groupings constructing, SSV withdrawal to the orbit of disposal, etc.

Electric CEU used for the orbital manoeuvring of "larger" space devices are marked by the greater value of thrust (for example, stationary plasma engines - up to 20W/MN and more), that makes them not applicable for SSV with limited electrical power supply. CEU with thermocatalytic micromotors with low thrust value have greater thrust (100-500 MN), that is unacceptable for SSV because of prohibitive disturbances at CEU working. Developed ammoniac CEU with electrothermal micromotor (ETMM) thrust $30 \mathrm{MN}$ is characterized by thrust value to 4W/MN and is successfully used in many SSV (Blinov V. N. et al., 2011, patents 2332583, 2442011, 2375267).

Ammoniac CEU operating principle is based on ammonia dissociating in ETMM with its decomposition into hydrogen and azote. It is possible to significantly increase ETMM thrust performance index due to double reduction of molecular mass of flowing out ammonia in comparison with ammonia gas. The processes of rapid high temperature dissociation of ammonia in ETMM in vacuum for various modes of functioning, project and design parameters define the effectiveness of CEU when solving the problems of orbital manoeuvring of SSV by the criterion of CEU reduced mass that uses ETMM thrust performance index and power consumed (Blinov V. N. et al., 2014)

When using ammoniac CEU with ETMM the problem of the quest for a compromise between thrust value and ETMM thrust performance index raises. Ammoniac CEU specific performances improving involves enhancement of their design and improvement of ammonia high temperature dissociating processes effectiveness for various methods, and of launching duration, power consumed. 


\section{Materials and Methods}

By their structural and methodical construction ammoniac CEU are designed for low-orbiting manoeuvrable SSV (MSSV) of various applications with the use of all-purpose design methods (guaranteed result method and structural approach) and dimensions \& mass method to calculate mass characteristics of CEU and their adaptation means to MSSV.

The efficiency estimation of all-purpose CEU developed according to the method of "guaranteed" result shows that best effectiveness is achieved for most "heavy" objective function from amongst feasible ones for CEU with fixed vectors of design and structural parameters. When performing all other objective functions all-purpose CEU effectiveness is always lower, even if these functions are closely approximated (Brusov, V. S., \& Baranov, S. K., 1989; Blinov et al., 2012).

\section{CEU effectiveness improvement can be achieved using structural access to CEU composition optimization.}

Let us present the range of $S^{*}$ design parameter vector, defining $C E U$ structural composition as:

$$
\mathrm{S}^{*}: \mathrm{S}_{\mathrm{B}} \times \mathrm{S}_{\mathrm{C}}
$$

where, $\mathrm{S}_{\mathrm{B}}-$ " $\mathrm{S}_{\mathrm{B}}$ " vector range, which defines base structure of all-purpose $\mathrm{CEU}$, used when solving all range of purpose-oriented problems;

$\mathrm{S}_{\mathrm{C}}$ - " $\mathrm{S}_{\mathrm{C}}$ " vector range, which defines component structures of all-purpose CEU used when solving separate purpose-oriented problems.

When forming a new structure of CEU in solving various purpose-oriented problems, we will have a number of CEU versions, which have the same base structure, but differ among themselves with components and associated systems composition.

When applying all-purpose research method of CEU design and structural layout for MSSV one of the relevant tasks of designing is a structural parametric synthesis carried out in the presence of current and expected variety of purpose tasks and conditions of MSSV use. Finding optimal structure and main design parameters of CEU at early designing stages makes it possible to reduce expenditures for CEU development providing the high execution effectiveness of purpose-oriented problems at hand.

Let us consider an interrelation of CEU design and structural parameters. CEU structure is understood to be its breakdown to systems and structure with an indication of connections between them, unchanged (according to the all-purpose method of guaranteed result) or changeable (according to the all-purpose method of structural design) and providing the idea of CEU as a complex system.

Reference speed set value realized by CEU in MSSV is taken as a MSSV object function: $\Delta \mathrm{V}_{\text {char }}{ }^{\mathrm{i}}\left(\mathrm{m}_{\mathrm{MSSV}}\right)=\Delta \mathrm{V}_{\text {char }}{ }^{\text {iset }}\left(\mathrm{m}_{\mathrm{MSSV}}\right)$. Applying all-purpose method of CEU designing, we assume that a range of object functions is already defined: $\left\{\Delta \mathrm{V}_{\text {char }}{ }^{\mathrm{i}}\left(\mathrm{m}_{\mathrm{MSSV}}\right)=\Delta \mathrm{V}_{\text {char }}{ }^{\text {iset }}\left(\mathrm{m}_{\mathrm{MSSV}}\right)\right\}$.

Fuel reserve in CEU for $\Delta \mathrm{V}_{\text {char }}$ iset $\left(\mathrm{m}_{\mathrm{MSSV}}\right)$ is determined using the value of ETMM thrust performance index $\mathrm{P}_{\mathrm{sp}}$ and CEU reduced mass $\mathrm{m}_{\mathrm{CEU}}^{\mathrm{Red}}$ as a part of MSSV. Let us present CEU reduced mass structural equation $\mathrm{m}_{\mathrm{CEU}}^{\mathrm{Red}}$ in the form of masses dependent and independent of fuel weight $\mathrm{m}_{\mathrm{F}}$ :

$$
\mathrm{m}_{\mathrm{CEU}}^{\mathrm{Red}}=\mathrm{m}_{\mathrm{FT}}+\mathrm{m}_{\mathrm{str}}+\mathrm{m}_{\mathrm{CEU}}^{\mathrm{Af}}+\mathrm{m}_{\mathrm{AUT}}+\mathrm{m}_{\mathrm{ETMM}}+\mathrm{m}_{\mathrm{R}}+\mathrm{m}_{\mathrm{OCN}}+\mathrm{m}_{\mathrm{CUCEU}}+\mathrm{m}_{\mathrm{F}}
$$

where $\mathrm{m}_{\mathrm{FT}}, \mathrm{m}_{\mathrm{str}}, \mathrm{m}_{\mathrm{CEU}}^{\mathrm{Af}}$ - mass of fuel container, structure, CEU adaptation means to MSSV composition, depending on fuel weight;

- $\mathrm{m}_{\mathrm{AUT}}, \mathrm{m}_{\mathrm{ETMM}}, \mathrm{m}_{\mathrm{R}}, \mathrm{m}_{\mathrm{OCN}}, \mathrm{m}_{\mathrm{CUCEU}}$ - mass of automatic equipment, ETMM, pipes, on-board cable network, control unit independent of fuel weight.

Working fuel reserve for ETMM set thrust performance index and MSSV reduced mass $m_{\text {CEU }}^{\text {Red }}$ define the value of realized reference speed, then,

$$
\mathrm{m}_{\mathrm{CEU}}^{\mathrm{Red}}=\mathrm{m}\left(\Delta \mathrm{V}_{\text {char }}\left(\mathrm{m}_{\mathrm{F}}, \mathrm{P}_{\mathrm{sp}}\right)\right)+\mathrm{m}_{\text {const }}
$$

(2) shows that all-purpose CEU base structures used for overall range of objective tasks solving are structures the mass of which does not dependent on fuel mass. Base structures are CEU - control unit; evaporator; pressure regulator valve; electro-valve; isolating valve; ETMM - electrical power supply; temperature control system; terminals containment system; heat element with insulation system; gas flow formation system. CEU component structures are fuel systems with structural parts. 
CEU mass characteristics and its adaptation means to MSSV are defined using the dimensions \& mass method according to the generalized formula:

$$
M=\sum_{i}^{n} \rho_{i} V_{i}
$$

where, $\rho_{i}, V_{i}$ - density and volume of the i-th element.

Let us examine CEU installed in MSSV in a special division with capability of movement in two orthogonally related directions for ETMM thrust vector setting (Figure 3) (patent 2375267).

Input parameter for all constructional elements dimensions calculation is fuel reserve $\mathrm{m}_{\mathrm{F}}$ and operating pressure in fuel container $\mathrm{p}^{\circ}$.

Thus, the radius of fuel cylindrical container $R_{\mathrm{t}}$ with egg ends $R_{\mathrm{sph}}\left(R_{\mathrm{sph}}=R_{t}\right)$ is defined via fuel reserves in CEU $\mathrm{m}_{\mathrm{F}}$ (Blinov V.N. et al., 2012):

$$
R_{t}=k_{t} \sqrt[3]{m_{F}} ; k_{t}=\sqrt[3]{\frac{k_{c}^{r}}{\gamma_{F} k_{\mathrm{ext}}^{r}}}
$$

where, $k_{t}=\sqrt[3]{\frac{k_{c}^{r}}{\gamma_{F} k_{\mathrm{ext}}^{r}}}$ - fuel container coefficient, with regard to the change of container geometry owing to extension value, gas binding and fuel density $\gamma_{\mathrm{F}}\left(k_{\mathrm{ext}}^{r}=\pi k_{\mathrm{ext}}+\frac{4}{3} \pi\right) ; k_{c}^{r}=1+\mathrm{k}_{\mathrm{c}} ; \mathrm{k}_{\mathrm{c}}$ - gas binding coefficient in the container); $k_{e x t}$ - fuel container extension coefficient $k_{e x t}=h_{t} / R_{t}$.

Aft ends wall thickness and cylindrical sections under the influence of operating pressure in the container $\mathrm{p}^{o}$ are defined using known strength constraints.

Plate dimensions for fuel container mounting are defined based in container and automatic equipment dimensions. For rectangular plate, lateral and longitudinal dimensions $l_{t}, l_{l}$ are defined by the dimensions of fuel container and coefficients $k_{t}, k_{l}$, with regard to dimensions increase for CEU automatic equipment installation:

$$
l_{t}=2 k_{t} R_{t} ; l_{l}=k_{l}\left(k_{\mathrm{ext}}+2\right) R_{t}
$$

In the plate for fuel container mounting cut is made with a dimension $2 \mathrm{R}_{\mathrm{t}}$ and $\left(k_{\mathrm{ext}}+2\right) R_{t}$. Strength elements thickness for designing initial stages is set based on analogues.

Using the given expressions, the following expression for CEU total weight is found according to dimensions \& mass method (Blinov V.N. et al., 2012):

$$
m_{\mathrm{CEU}}^{(F)}=m_{F}\left(p^{o} K_{t}^{\mathrm{gen}}\left(1+k_{\mathrm{ext}}\right)+m_{F} K_{p}^{\mathrm{gen}}\right)+\sqrt[3]{m_{F} k_{l}} k_{t}
$$

where, $K_{t}^{\text {gen }}=\frac{\gamma_{m}}{\sigma_{b}} 2 \pi k_{t}^{3} n k_{w}-$ container cylindrical section generalized factor, considering density $\gamma_{\mathrm{m}}$ and break point stress under tension $\sigma_{\mathrm{b}}$ of construction material, fuel container coefficient $k_{t}$, safety coefficient $\mathrm{n}$, weight coefficient $k_{w}$, considering container wall thickening in respect to minimal permissible value;

$K_{p}^{g e n}=\left(2 k_{t} k_{l}\left(k_{\text {ext }}+2\right)-2\left(k_{\text {ext }}+2\right)\right) K_{F}^{p} \gamma_{p} K_{t}^{3}$ - plate generalized factor for mounting fuel container, considering lateral and longitudinal plate dimensions for mounting fuel container $\left(l_{t}=2 k_{t} R_{t} ; l_{l}=k_{l}\left(k_{\mathrm{ext}}+\right.\right.$

2) $\left.R_{t}\right) ; \quad k_{F}^{p}=\frac{\delta_{w}^{p}}{R_{t}}$ - plate reduced thickness coefficient, considering ratio of plate weight thickness $\delta_{w}^{p}$ to

fuel container radius; $\gamma_{p}$ - platform material density;

$k_{l}=4 \pi F \gamma_{l}$ - lodgement reduced factor for mounting container with a square of $F_{l}$ and material specific gravity $\gamma_{l}$.

Let us write the structural mass equation of CEU adaptation means to MSSV with movable in two orthogonally 
related directions $\mathrm{CEU}$ when setting ETMM thrust vector $\mathrm{m}_{\mathrm{CEU}}^{\mathrm{Af}}$ as:

$$
m_{\mathrm{CEU}}^{\mathrm{Af}}=2 m_{F}^{p}+m_{\mathrm{CEU}}^{p}+4 m_{r}+m_{\mathrm{CEU}}^{\mathrm{MSSV}}
$$

where, $m_{F}^{p}$ - the mass of the end plate of MSSV division for CEU;

$m_{\mathrm{CEU}}^{p}-$ the mass of the plate for mounting CEU in MSSV;

$m_{r}$ - the mass of 4 stands for fastening and moving CEU when setting ETMM thrust vector;

$m_{\mathrm{CEU}}^{\mathrm{MSSV}}-$ the additional mass of MSSV lateral plates for CEU installation.

The mass of end plate with diagonal supports (we assume its dimensions as $l_{t}, l_{l}$ ):

$$
\begin{gathered}
\mathrm{m}_{F}^{\mathrm{p}}=2\left(l_{t}+l_{l}+\sqrt{l_{t}^{2}+l_{l}^{2}}\right) F_{S 1}^{\mathrm{red}} \gamma_{\mathrm{m}}^{\mathrm{p}}=2\left(2 k_{t} R_{t}+k_{l}\left(k_{\mathrm{ext}}+2\right) R_{t}+\right. \\
\left.+\sqrt{\left.\left(2 k_{t} R_{t}\right)^{2}+k_{l}\left(k_{\mathrm{ext}}+2\right) R_{t}\right)^{2}}\right) F_{S 1}^{\mathrm{red}} \gamma_{\mathrm{m}}^{\mathrm{p}}
\end{gathered}
$$

where $F_{S 1}^{\text {red }} \gamma_{\mathrm{m}}^{\mathrm{p}}$ - the reduced area of section and density of end plate beams material.

We also assume the dimensions of plate for CEU installation without diagonal supports as $l_{t}, l_{l}$, and then its mass will be

$$
\mathrm{m}_{\mathrm{CEU}}^{p}=2\left(l_{t}+l_{l}\right) F_{S 2}^{\mathrm{red}} \gamma_{\mathrm{m}}^{\mathrm{p}}=2\left(2 k_{t} R_{t}+k_{l}\left(k_{\mathrm{ext}}+2\right) R_{t}\right) F_{S 2}^{\mathrm{red}} \gamma_{\mathrm{m}}^{\mathrm{p}}
$$

where $\quad F_{S 2}^{\text {red }}$ - the reduced area of plate beams section for CEU installation.

Stand mass with a length $l_{r}$, cross sectional area $\mathrm{F}_{r}$ and material density $\gamma_{r}$ for fastening and moving CEU:

$$
m_{r}=l_{r} F_{r} \gamma_{r}=\left(2 R_{t}+h_{\text {aut }}+h_{\mathrm{CU}}+2 h_{\mathrm{reg}}\right) F_{r} \gamma_{r}
$$

where $h_{\mathrm{aut}}, h_{\mathrm{CU}}$ - the altitude of automatic equipment protrusion and two control units towards the fuel container;

$h_{\text {reg }}$ - increase in stands length due to position control of DUMIT when setting ETMM thrust vector.

In order to define $m_{\mathrm{CEU}}^{\mathrm{MSSV}}$ let us introduce the constant coefficient mass load of lateral plates - structural weight

$m_{\mathrm{p}}^{\text {side }}$ of SSV for the volume they occupy in the following way:

$$
k_{V}^{m}=\frac{m_{p}^{\text {side }}}{V_{\mathrm{SSV}}}=\mathrm{const}
$$

Then, if CEU as a part of MSSV occupies volume $V_{\mathrm{CEU}}$ and the dimensions of CEU define cross dimensions of MSSV (what is fair for this MSSV layout):

$$
\mathrm{m}_{\mathrm{CEU}}^{\mathrm{MSSV}}=k_{V}^{m} V_{\mathrm{CEU}}=k_{V}^{m}\left(2 k_{t} k_{l}\left(k_{\mathrm{ext}}+2\right) R_{t}^{2}\right) k_{t}^{i} k_{l}^{i} l_{r}
$$

where $k_{t}^{i}, k_{l}^{i}$-coefficients, determining cross dimensions of MSSV owing to $l_{t}, l_{l}$ extension.

The presented dependences demonstrate interaction of CEU design $\left(m_{F}, P_{\mathrm{sp}}\right)$, structural parameters and CEU adaptation means as a part of MSSV. A preference for all-purpose design method is driven by the extent of difference of objective problems among set ones with MSSV design layout change estimation: dimensions, mass. MSSV design layout change subject to objective tasks difference degree is defined with regard to CEU accepted arrangement as a part of MSSV.

The required fuel reserves for objective function $\Delta V_{\text {char }}^{i}\left(m_{\mathrm{MSSV}}\right)=\Delta V_{\text {char }}{ }^{i \text { set }}\left(m_{\mathrm{MSSV}}\right)$ realization are estimated (for MSSV with a mass of 100, $500 \mathrm{~kg}$ and ETMM with a power consumption of $60 \mathrm{~W}$ as an illustration of CEU with ETMM on ammonia when cold starting ETMM (simultaneous fuel and voltage input) (Figure 1). 


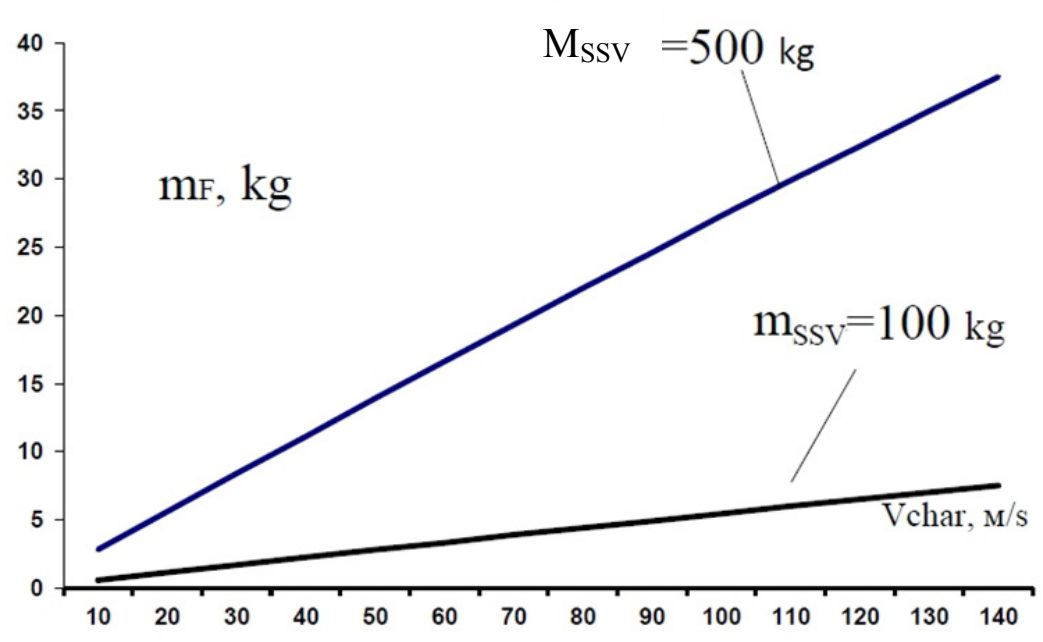

Figure 1. CEU fuel weight dependence on MSSV reference speed

This dependence shows that feasibility of shift from the method of "guaranteed" result to the method of structural design when constructing all-purpose satellite platform (ASP) of MSSV is carried out based on the analysis of objective functions differences degree and ASP dimensions and mass characteristics.

The experience of MSSV constructing based on various all-purpose ASP for a mass range of (30-40) kg; (40-70) $\mathrm{kg}$; (70-120) kg; (120-200) kg; (200-500) kg showed that MSSV structure can be referred to both base structure

$\left(s_{b}^{\text {str }}\right)$ and component structure $s_{c}^{\text {str }}$ (Blinov V. N. et al., 2012).

It's concluded based on the analysis of constructed ASP and MSSV that for a MSSV mass range of (30-40), $(40-70) \mathrm{kg}$ the structure, as a rule, is a component structure and it is developed according to the structural method depending on the current objective task of MSSV (Blinov V.N. et al., 2012).

When increasing MSSV mass range the method of structural decomposition of ASP is defined based on the analysis of orbital manoeuvring tasks and used methods of MSSV designing in general.

Thus for MSSV ERS with a mass of to $250 \mathrm{~kg}$ a preference is given to a ASP scheme wherein frame structure with plates, on which base structures of APS support systems, optoelectronic system and CEU (frame arrangement) are mounted, is used as a base structure (patent 2457157). Given this, both the guaranteed result method and the structural design method can be applied.

When designing MSSV with CEU embedded in the instrument unit, a combined approach can be used to increase the guaranteed result method effectiveness (Figure 2) (Blinov V.N. et al., 2012):

- Instrument unit development according to the guaranteed result method;

- CEU designing according to the structural design method. 


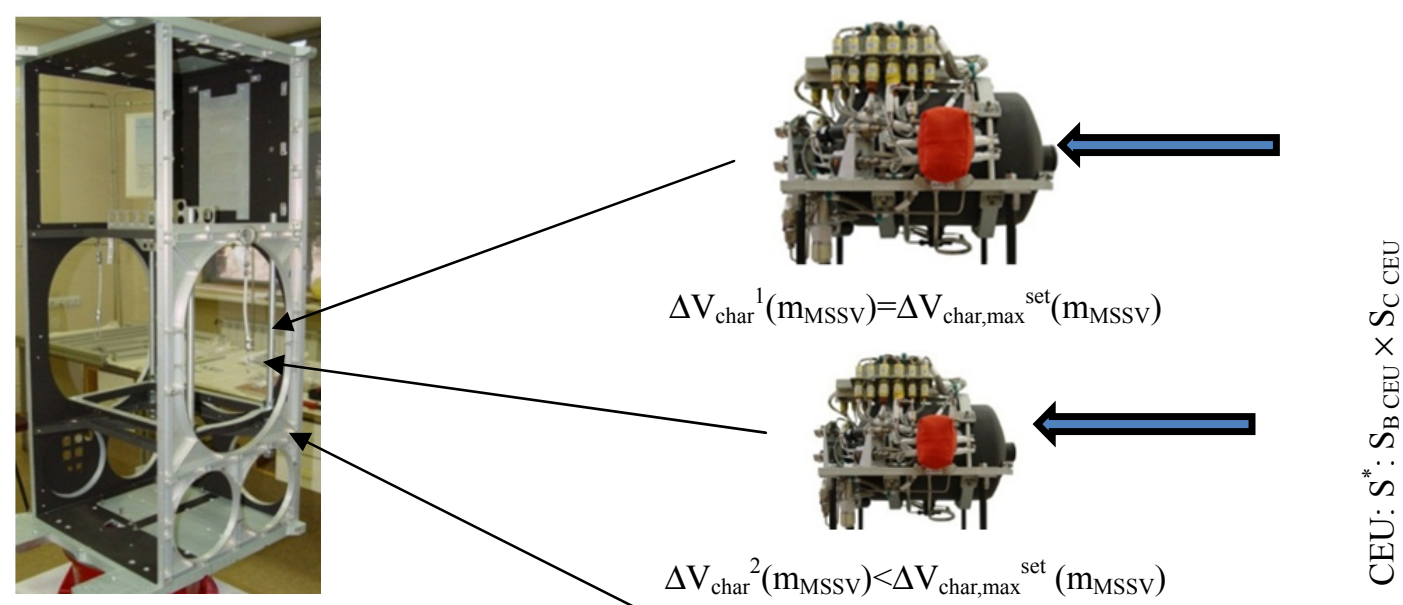

(guaranteed result method)
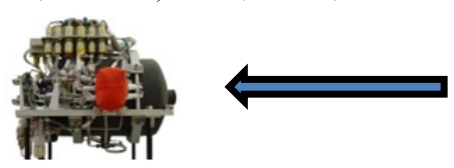

$$
\Delta \mathrm{V}_{\text {char }}{ }^{\mathrm{n}}\left(\mathrm{m}_{\mathrm{MSSV}}\right)<\ldots<\Delta \mathrm{V}_{\text {char,max }}{ }^{\text {set }}\left(\mathrm{m}_{\mathrm{MSSV}}\right)
$$

Figure 2. The use of structural optimization method for $\mathrm{CEU}$ and the guaranteed result method for instrument unit

The issues of the CEU design layout selection is intimately connected with the task of CEU adaptation in MSSV and the selection of ETMM thrust vector-setting system. Thrust vector-setting systems are based either on the displacement of all CEU in two orthogonally related directions or ETMM turn (Figure 3-5).
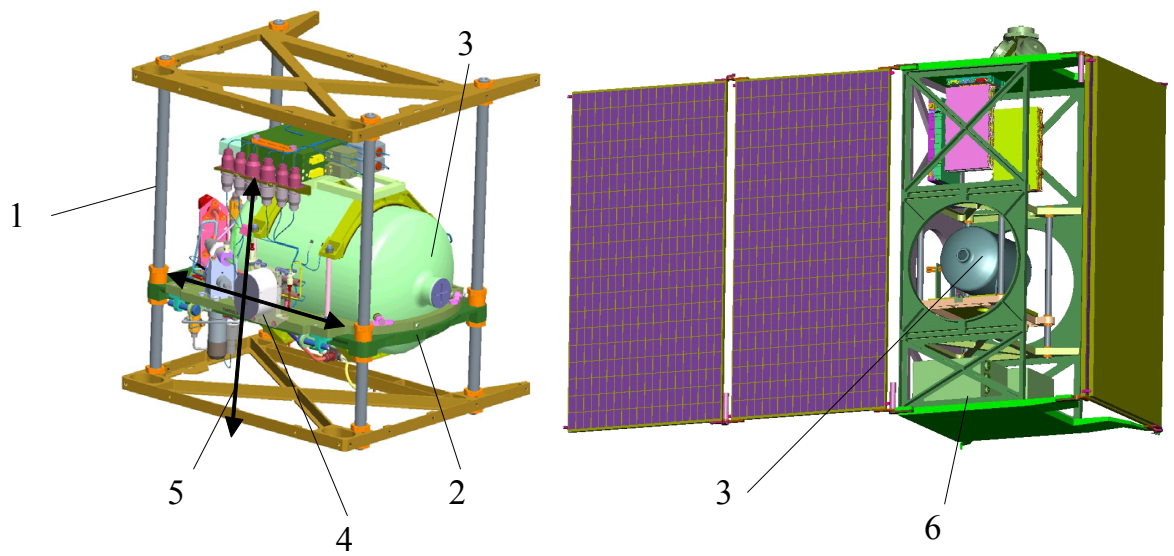

1 - thread stand (4 pcs.); 2 - movable plate; 3 - CEU; 4 - ETMM; 5 - directions of CEU displacement; 6 - SSV

Figure 3. ETMM thrust vector-setting system with CEU displacement for CEU configuration central cheme 


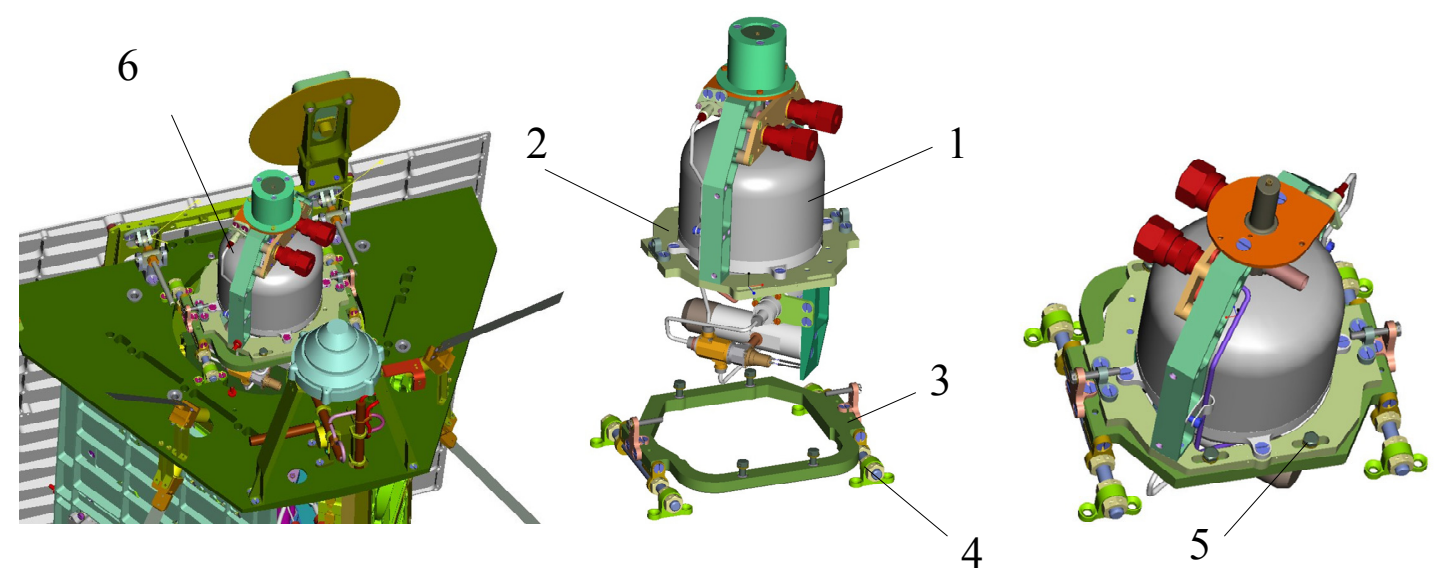

1 - CEU; 2 - CEU plate; 3 - CEU moving plate; 4 - CEU displacement node of screw-and-nut type; 5 -slots of CEU plate displacement; 6 - CEU front installation scheme in SSV.

Figure 4. ETMM thrust vector-setting system with CEU displacement for CEU front configuration

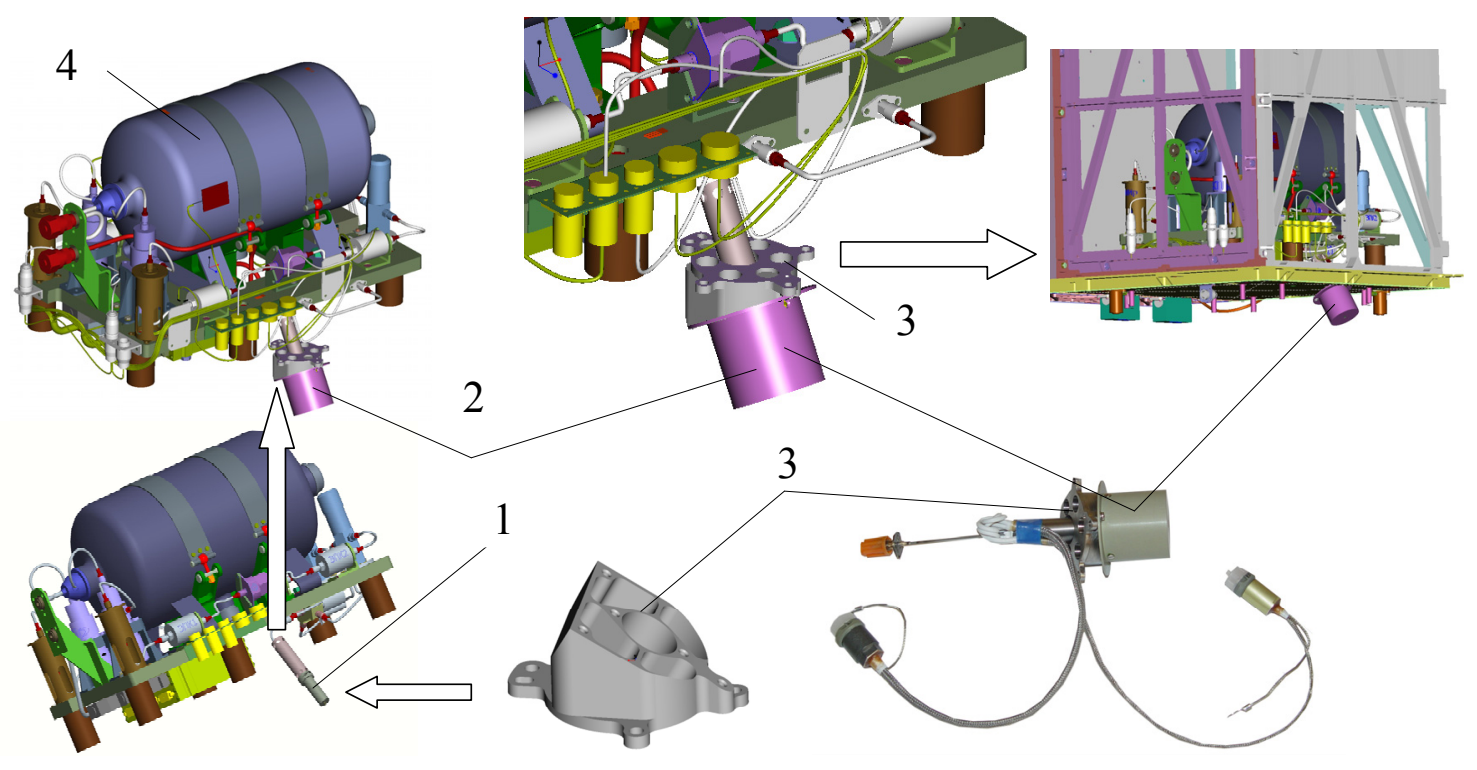

1 - ETMM without heat-protective cover; 2 - ETMM with heat-protective cover; 3 - pad orienting ETMM thrust vector ETMM in the direction through the centre of mass of SSV; 4 - CEU

Figure 5. ETMM thrust vector-setting system with ETMM displacement due to the pad

The application of structural method allows searching for optimal structural solutions without feasible alternative structures initial set previous construction (Figure 6). 


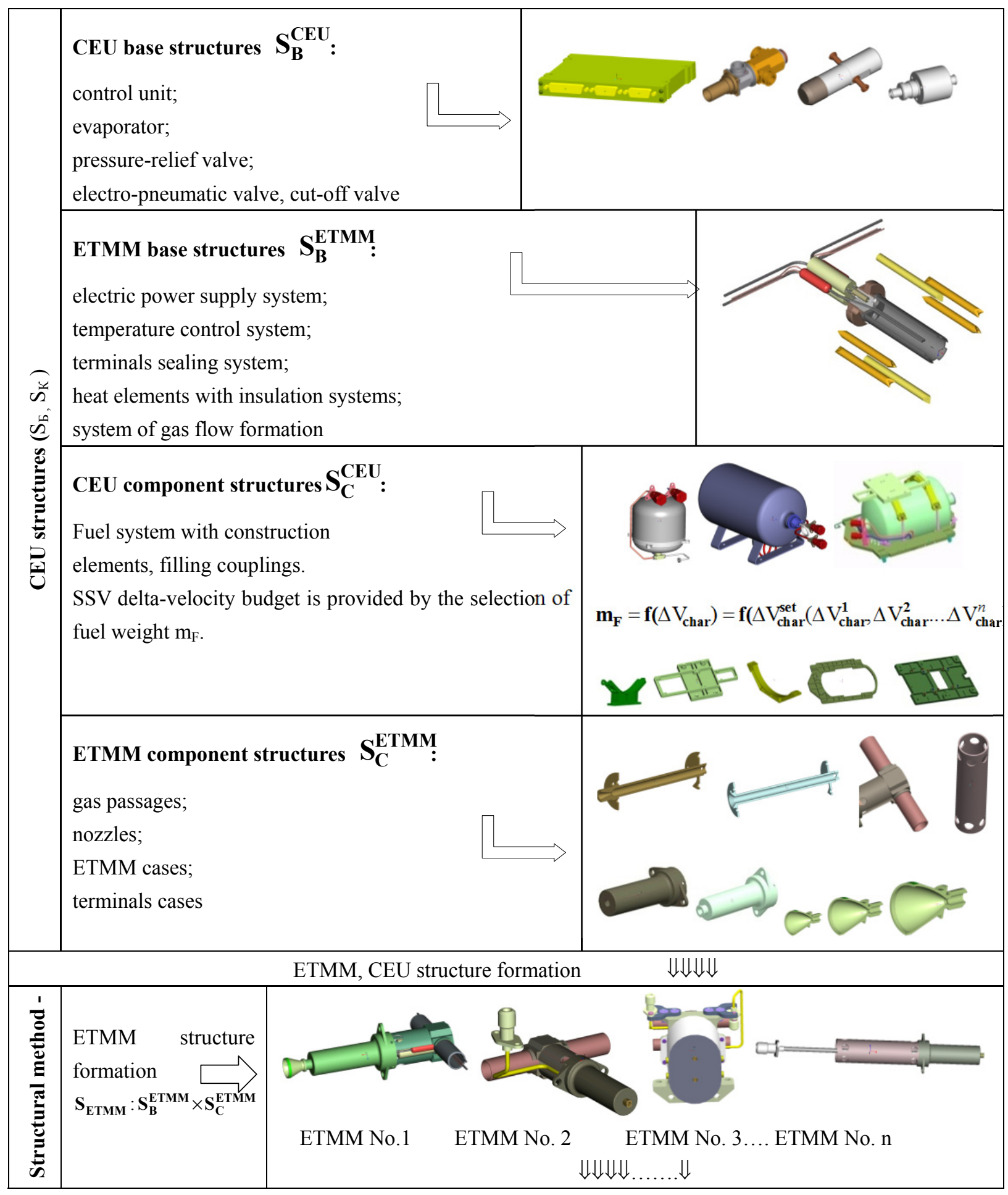




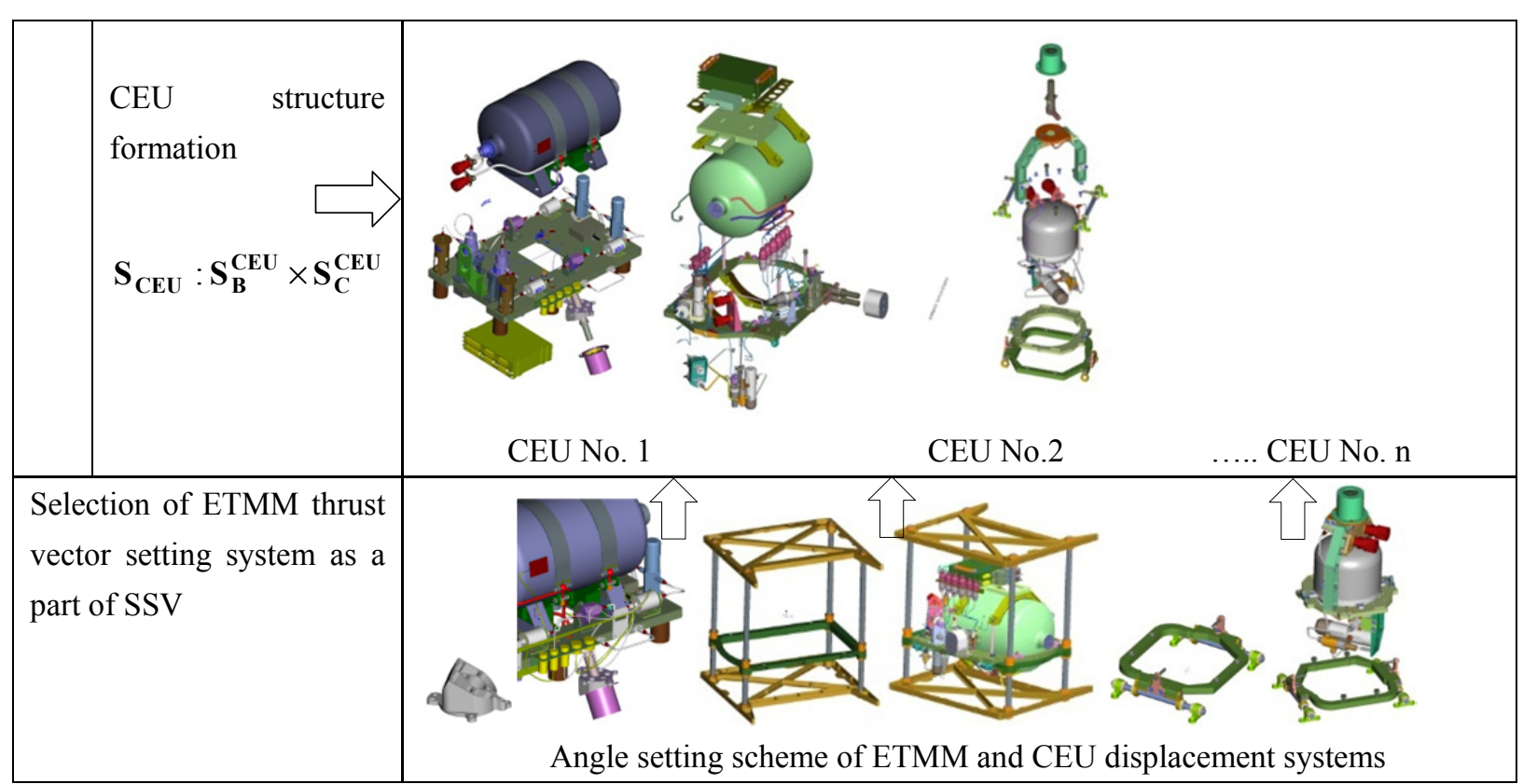

Figure 6. Scheme of CEU design layout formation

CEU operation studies were carried out in accordance with ammoniac CEU scheme functioning (Figure 7) (Blinov V.N., 2014). 


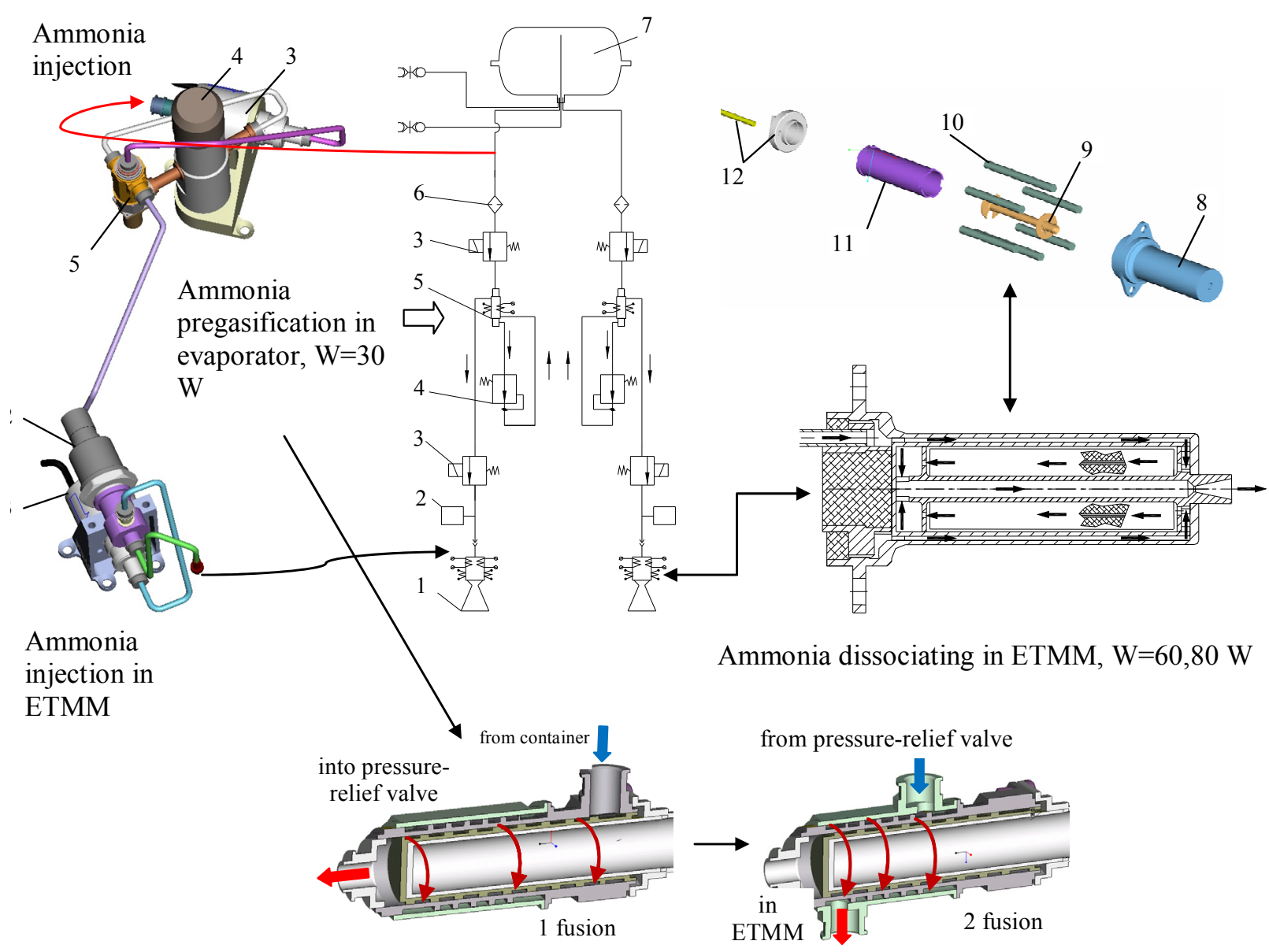

1 - ETMM; 2 - pressure switch; 3 - electro-pneumatic valve; 4 - pressure-relief valve; 5 - ammonia evaporator; 6 - filter; 7 - ammonia container; 8 - outer case; 9 - gas passage with a nozzle; 10 - electric heater; 11 - inner case; 12 - clamping nut with ammonia feeding line

Figure 7. Ammonia high temperature dissociation scheme in redundant ammoniac CEU with two ETMM

Ammonia pregasification takes place in double-threaded evaporator according to the pattern: liquid ammonia gasification in first heating piping - ammonia injection into pressure-relief valve - ammonia injection into second heating piping - ammonia injection into ETMM.

Ammonia dissociating flows in ETMM with tubular elements, consisting of two channel ceramic pipes with heaters in them in the form of nichrome wire (patent 2332583, 2442011). Heat elements (main and reserve) are located around the gas passage of ETMM. ETMM power consumption used when CEU operates is $60.80 \mathrm{~W}$.

ETMM structure provides the following scheme of ammonia gas flow passing:

- spinning when ammonia passes between frame structures;

- contact with heat elements;

- passing through gas passage with gas discharge through a nozzle.

This scheme of ammonia passing provides uniformity and increase in ammonia heating time in ETMM when only main or only reserve heating elements work, which are located around the gas passage radially in opposition. To reduce thermal losses during ammonia dissociating in EMTT the insulation bedded in heat-shielding casing is used, consisting of fabric HWK-0.05 TU 6-48-05-786904-151-95, foil, alloy IV3V,8 $\mu \mathrm{m}$ TU 48-21-151-84.

Structural scheme of heat-protective casings for various designs and structures of ETMM is shown in Figure 8. 

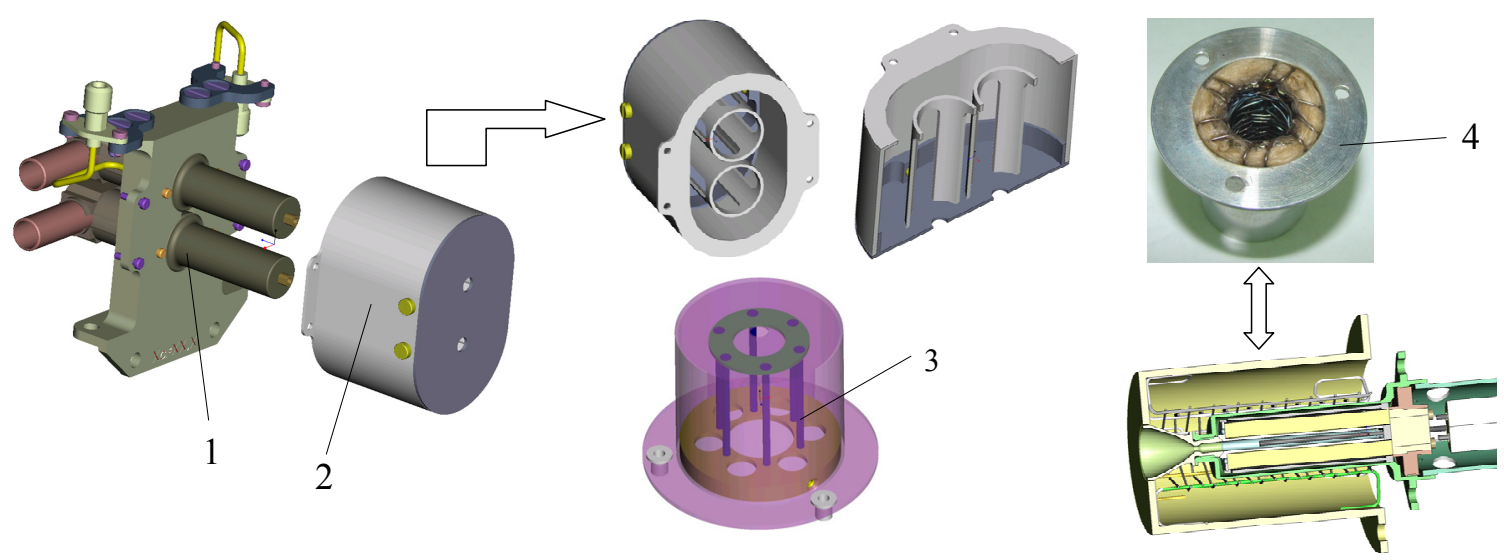

1- unit consisting of two ETMM; 2 - heat-protective casing of ETMM unit; 3 - heat-protective casing of rod type; 4 - heat-protective casing of reticulate type

Figure 8. Structural schemes of heat-protective casings

CEU is controlled by means of the execution of commands, accepted by control unit. CEU control algorithm operates:

- directly in CEU control unit owing to control program execution in accordance with flexible cyclogram, parameters of which can be changed using input data (pre-set values),

- by means of the execution of onetime temporary commands from SSV on-board control system.

To manage CEU external (transmitted to SSV board from a ground control post) and additional commands are used. Control unit external commands are formed in the form of temporary commands of SSV on-board control system at a ground control post, are transmitted to SSV board during communication session, and then in the form of CAN interface command are transmitted to connected current (main or reserve) CEU control unit at the set time.

Maximum operate time of electro valves is CEU working time limit in the mode of developing thrust for the purpose of overheating prevention. Moreover, when CEU operates SSV pointing and attitude control system identifies disturbing torques occurring at ETMM operating. CEU control unit periodically compares current kinetic momentum of SVV hand wheels control motors with given range of torques and in case of overrunning generates command for CEU shutdown.

By means of CEU control program selection the pre-set type of starting (cold and hot), CEU running time at single start, and evaporator and ETMM power consumption distribution by time are realized. Realizable control parameters of CEU control eventually defines ETMM thrust performance index.

ETMM hot launching cyclogram involves structure preheating and gasified ammonia injection in EMTT (Figure 9). ETMM cold starting cyclogram involves gasified ammonia injection in ETMM with simultaneous switching of heating elements (Figure 10). 


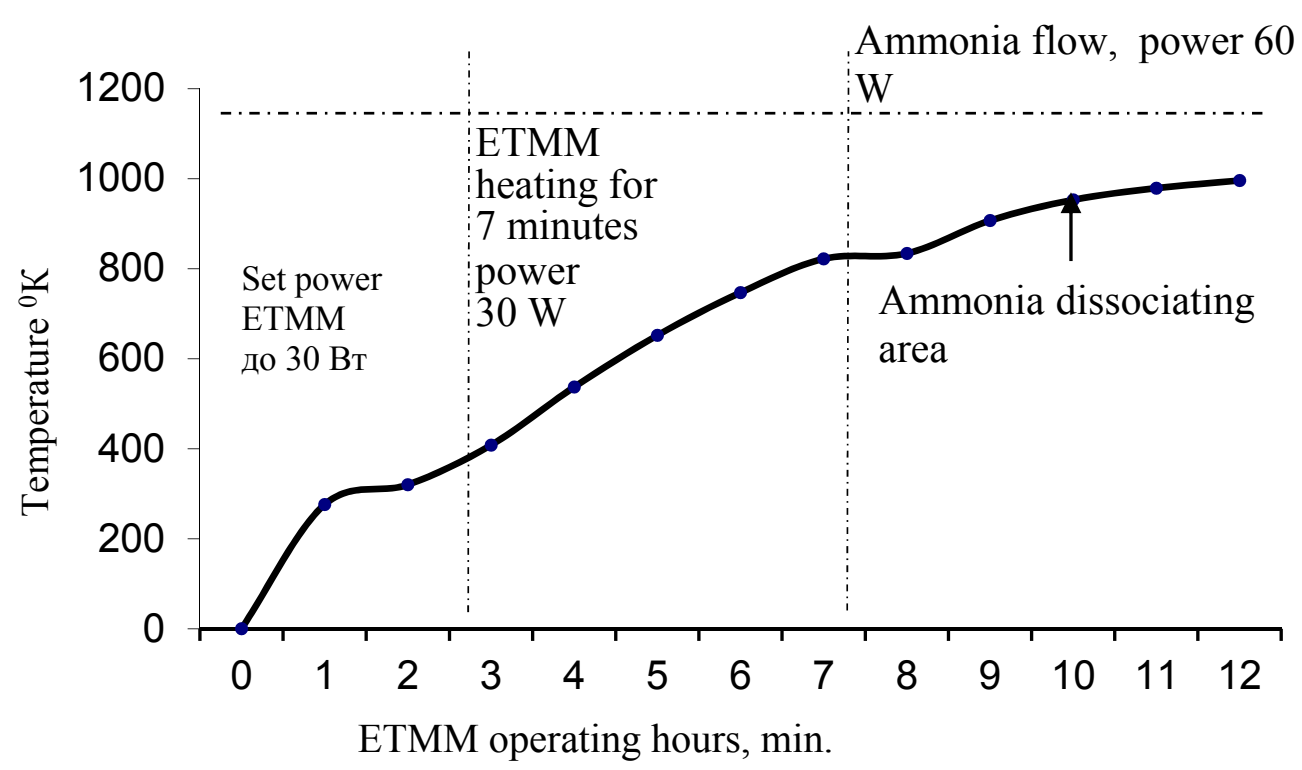

Figure 9. Typical temperature change of ETMM structure and ammonia gas in ETMM at hot starting in vacuum

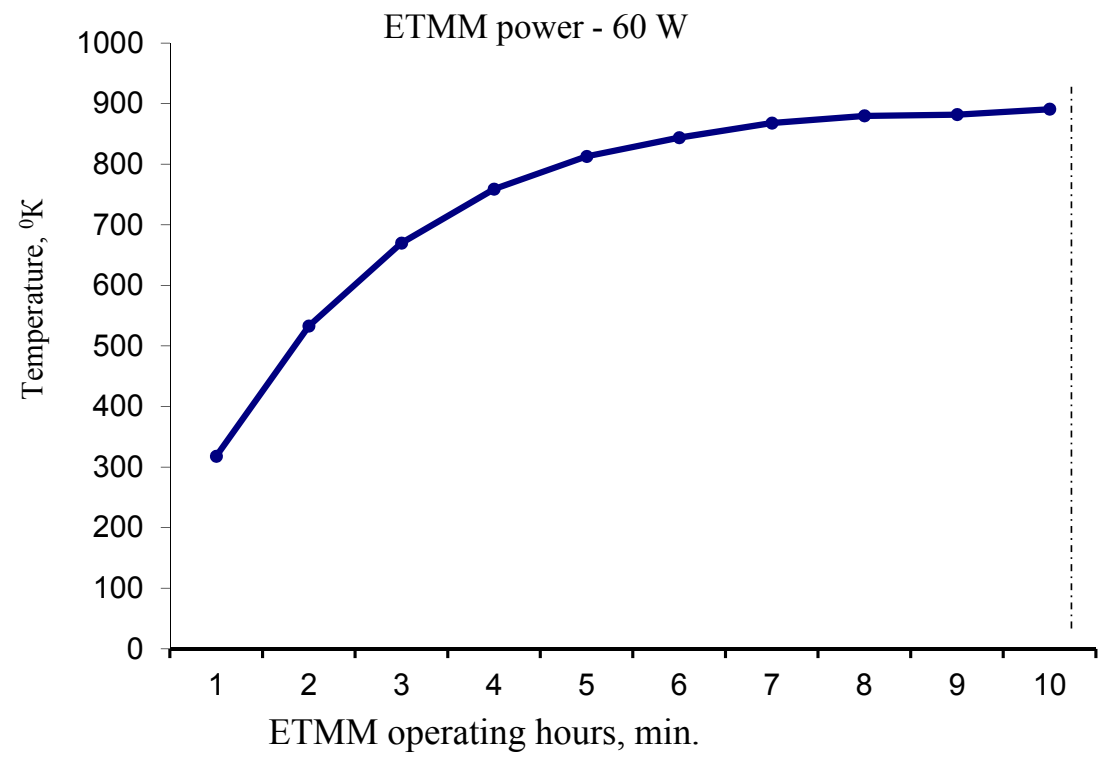

Figure 10. Typical temperature change of ammonia gas in ETMM at cold starting in vacuum

The disadvantage of cold starting is ETMM low reliability because of heaters' possible burning due to the lack of heat pickup when heating up the structure.

Ammonia temperature at the inlet to ETMM nozzle throat section is measured using two embedded thermocouples of TXA type, pressure - using pressure switch in CEU piping. CEU control unit measures electrical parameters (power, current, resistance).

\section{Results and Discussion}

The design method of CEU and ETMM with convertible and extensible structure was used for ammoniac CEU construction with a fuel reserve of $2.7 \mathrm{~kg}, 4.0 \mathrm{~kg}$, and $0.4 \mathrm{~kg}$ (Figure 11-13). 

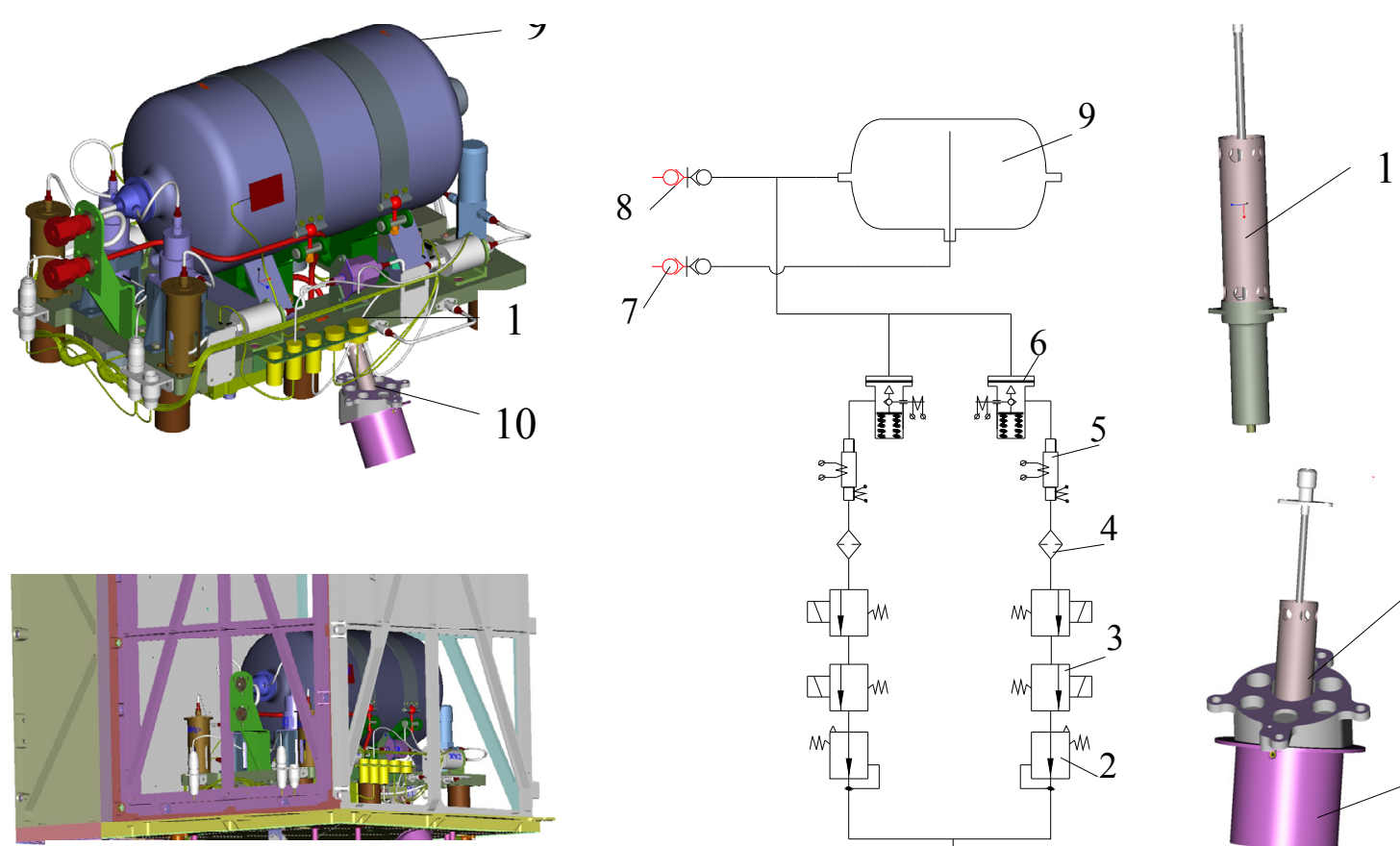

CEU as a part of SSV
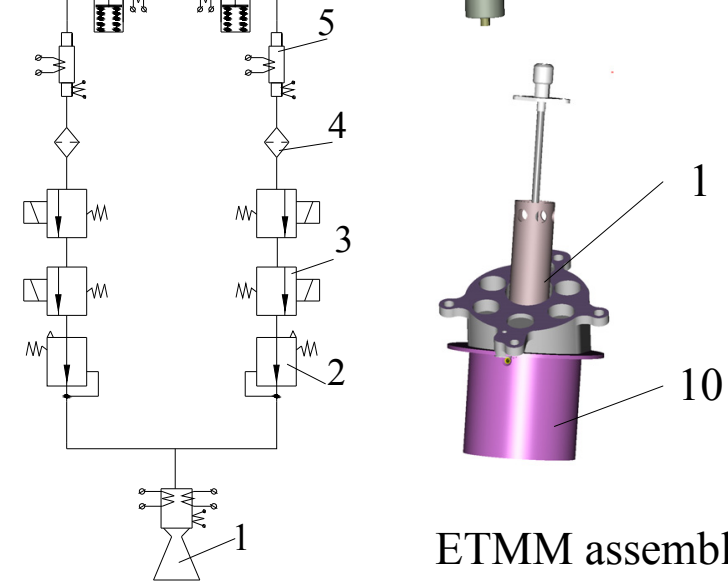

ETMM assembled

1 - ETMM; 2 - pressure-relief valve; 3 - electro-pneumatic valve; 4 - filter; 5 - evaporator; 6 - breakthrough valve; 7 - vent coupling; 8 - filling coupling; 9 - fuel container; 10 - ETMM heat-protective cover.

Figure 11. Redundant ammoniac CEU with one ETMM and fuel reserve of $2.7 \mathrm{~kg}$
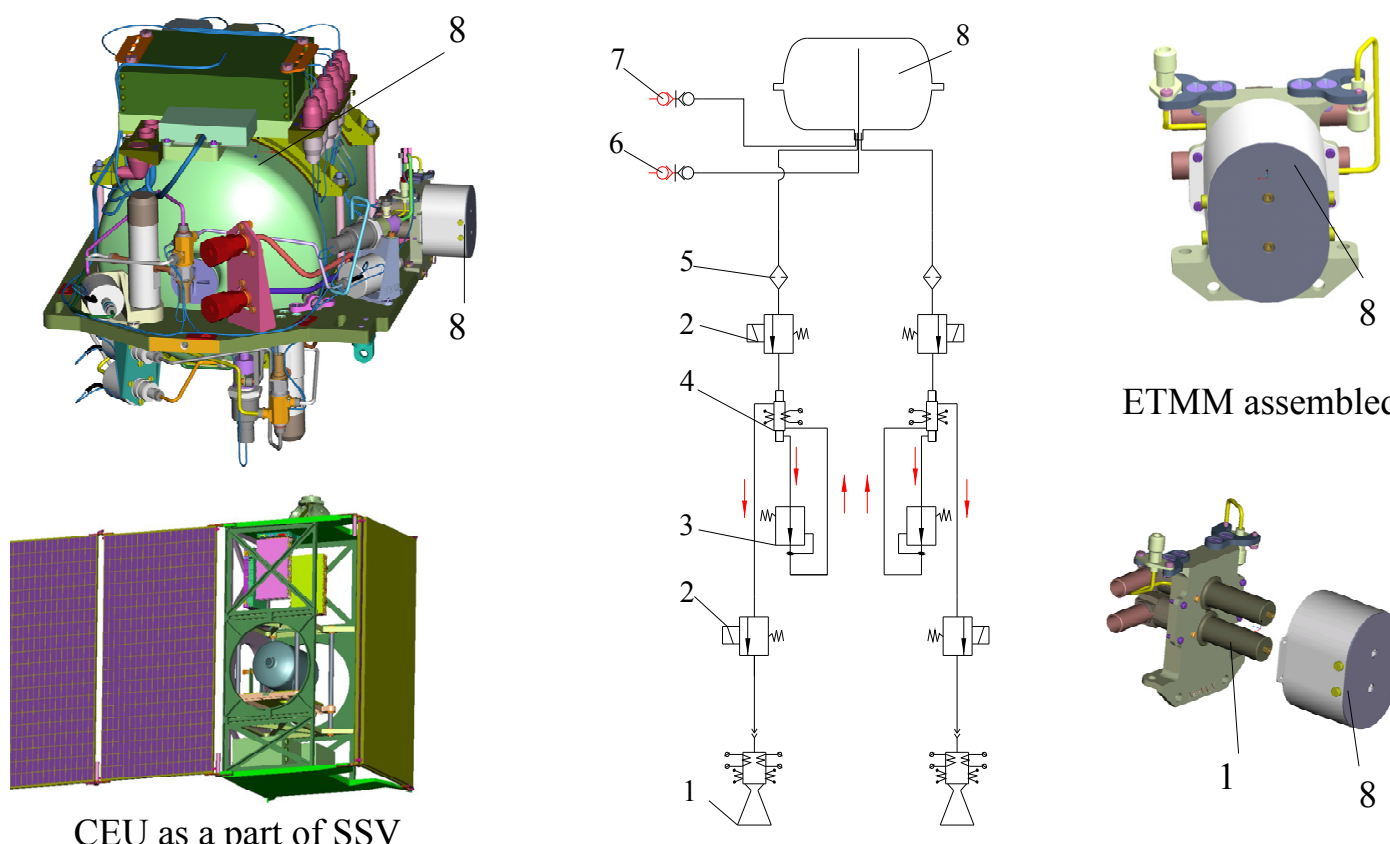

CEU as a part of SSV

1 -ETMM with heat-protective casing; 2 - electro-pneumatic valve; 3 - pressure-relief valve; 4 - evaporator; 5 filter; 6 - vent coupling; 7 -filling coupling; 7 - fuel container; 8 - ETMM heat-protective casing

Figure 12. Redundant ammoniac CEU with two ETMM and a fuel reserve of $4.0 \mathrm{~kg}$ 


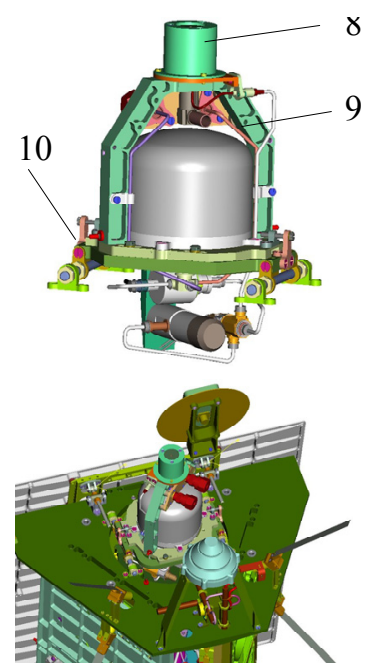

CEU as a part of SSV

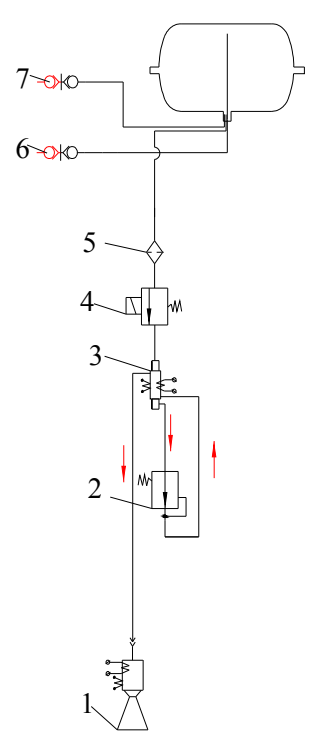

1 - ETMM (heat-protective casing is not shown); 2 - pressure-relief valve; 3 - evaporator; 4 - electro-pneumatic valve; 5 - filter; 6 - vent coupling; 7 - filling coupling; 8 - ETMM heat-protective casing; 9 - fuel container; 10 -thrust vector setting system

Figure 13. Non-redundant ammoniac CEU with one ETMM and a fuel reserve of $0.4 \mathrm{~kg}$

Ammoniac ETMM with conic nozzle with T-shaped (a), coaxial (b) and L-shaped (c) configuration of terminals of nominal thrust $30 \mathrm{MN}$ are developed for CEU (Figure 14).

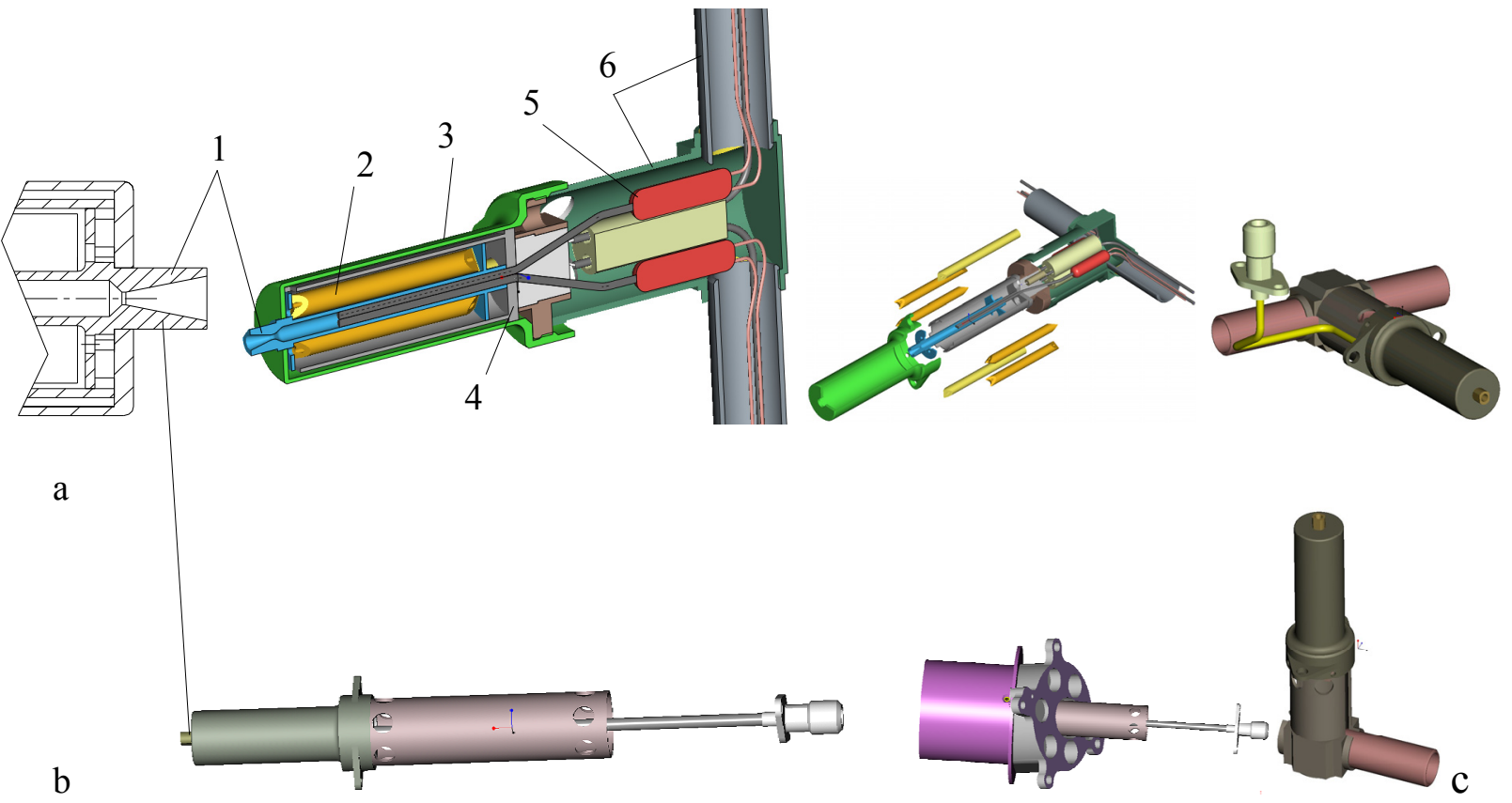

1 - gas passage with conic nozzle; 2 - tubular heating element (main and reserve); 3 - casing; 4 - flanged can; 5 - thermocouple; 6 - terminals casing

Figure 14. ETMM structural scheme with conic nozzle with T-shaped (a), coaxial (b) and L-shaped (c) configuration of terminals 
CEU main characteristics:

- ETMM thrust-30 MN;

- power consumption (a, b): CEU in total - 100W; ETMM - 60W; evaporator - 30W;

- power consumption (c): CEU in total - 57W; ETMM - 30W; evaporator-20W;

- thrust performance index - $2500 \mathrm{~m} / \mathrm{s}(\mathrm{a}, \mathrm{b}) ; 2300 \mathrm{~m} / \mathrm{s}(\mathrm{c})$;

- ammonia filling weight: $2.7 \mathrm{~kg}(\mathrm{a}), 4.0 \mathrm{~kg}(\mathrm{~b})$ and $0.4 \mathrm{~kg}(\mathrm{c})$;

- reliability support $(\mathrm{a}, \mathrm{b})$ : unit control, pneumatic-hydraulic systems, ETMM heating elements, ETMM redundancy (b); cold starting use, the use of ETMM two control channel by temperature and power.

The distinctive design peculiarities of ETMM with a conic nozzle are:

- conic nozzle implementing together with a gas passage;

- electrical wire (nichrome) heating elements (main and reserve) location out of gas passage in two-channel ceramic tube;

- gas passage location with heating elements in a ring flanged cylindrical can;

- cylindrical can location with gas passage and heating elements inside cylindrical body;

- installation of contact elements of two thermocouples for temperature control in gas passage;

- gas flow vortex in the form of diagonal gas-feed cuts in can ring flange, which contacts casing inside surface.

For ETMM with a conic nozzle an increased heating (35-40\%) of ammonia gas in comparison with analogues, $30-35 \%$ increase in fuel gas spinning are provided.

The operation of ETMM with a conic nozzle made conjointly with gas passage showed its effectiveness. However when pressure at the inlet of ETMM critical nozzle is approximately $0.05 \mathrm{MPa}$, the diameter of nozzle throat section is small $(0.7 \mathrm{~mm})$. Therefore, technologic difficulties arise concerning its production.

Pressure at the inlet of critical nozzle should be reduced to $0.02 \mathrm{MPa}$ in order to increase nozzle throat section diameter. Given this, nozzle throat section diameter increases to $1 \mathrm{~mm}$ and its production and control present no technologic problems.

On the other hand, one of the ways of ETMM thrust performance index increase is the use of a bell nozzle. The optimal diameter of bell nozzle cut for nozzle throat diameter of $1 \mathrm{~mm}$ is $10 \mathrm{~mm}$. In ETMM with a conic nozzle, the maximum diameter of nozzle section is defined by the gas passage outer diameter, which cannot be more than $3 \ldots .5 \mathrm{~mm}$ in view of design features. At such dimensions bell nozzle will have non-optimum characteristics. That is why using all-purpose method the ammoniac ETMM with an opportunity of bell nozzle installation was constructed (Figure 15). 


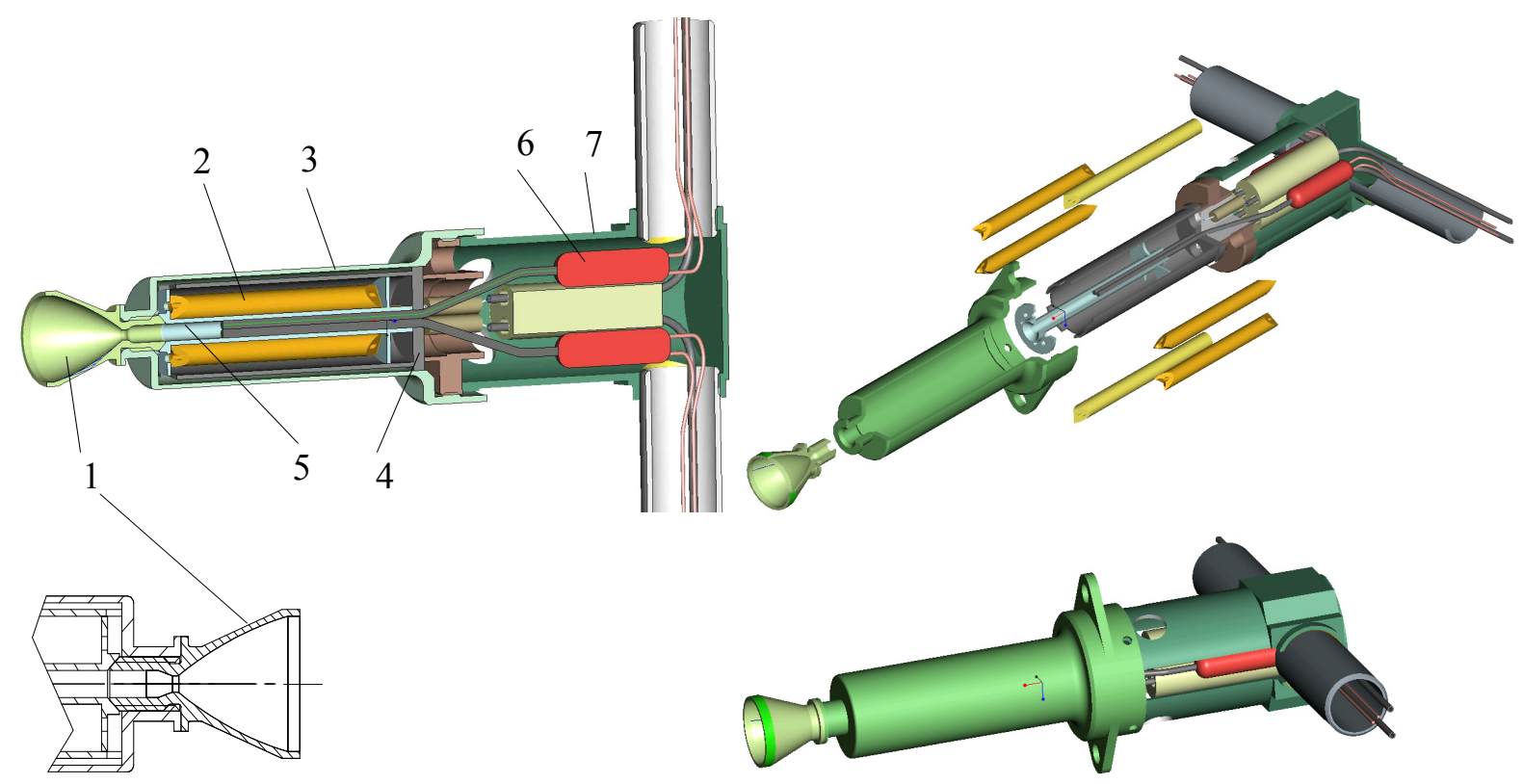

1 - nozzle; 2 - tubular heating element (main and reserve); 3 - casing; 4 - flanged can; 5 - gas passage; 6 thermocouple; 7 - terminals casing

Figure 15. ETMM structural scheme with a bell-shaped nozzle with T-shaped configuration of terminals

Constructed ETMM allows using various bell nozzles far different by characteristics without main structure change. It is provided by means of bell nozzle executing in the form of separate removable nozzle insert put in ETMM body and contacting gas passage end surface providing gas inlet to the nozzle. The use of a bell nozzle makes it possible to increase ETMM thrust performance index by $(10-15) \%$, and significantly improve the operational characteristics of nozzle production.

Ammonia gas $\left(\mathrm{T}_{\mathrm{OM} 1}, \mathrm{~T}_{\mathrm{OM} 2},{ }^{\circ} \mathrm{K}\right)$ temperature changes and changes in evaporator casing temperature $\left(\mathrm{T}_{\mathrm{OE} 1}\right.$, $\mathrm{T}_{\mathrm{OE} 2},{ }^{\circ} \mathrm{K}$ ) are shown in Figure 16-19 for ETMM with a conic nozzle.

ETMM cold starting guarantees heating elements integrity maintenance and is considered main starting method of ETMM.

Cold starting efficiency upgrading can be achieved by the increase in power consumption and ETMM operating time at single starting.

At ETMM cold starting with a capacity of $60 \mathrm{~W}$, duration from 3 to 10 minutes, temperature in ETMM vessel hit the range from $731^{\circ} \mathrm{K}$ to $890^{\circ} \mathrm{K}$. When increasing ETMM operation time to 20 minutes, the predicted temperature will be up to $913-923^{\circ} \mathrm{K}$. At dissociating power consumption of $80 \mathrm{~W}$ ammonia, the temperature increases by $373-393^{\circ} \mathrm{K}$.

The use of hot starting of ETMM is only possible when providing heating elements reliability by means of development of heat removal system from heaters during ETMM heating.

At ETMM short switching in accordance with "hot" scheme from 2 to 5 minutes long temperature in ETMM vessel reached the range from $847^{\circ} \mathrm{K}$ to $999^{\circ} \mathrm{K}$. 


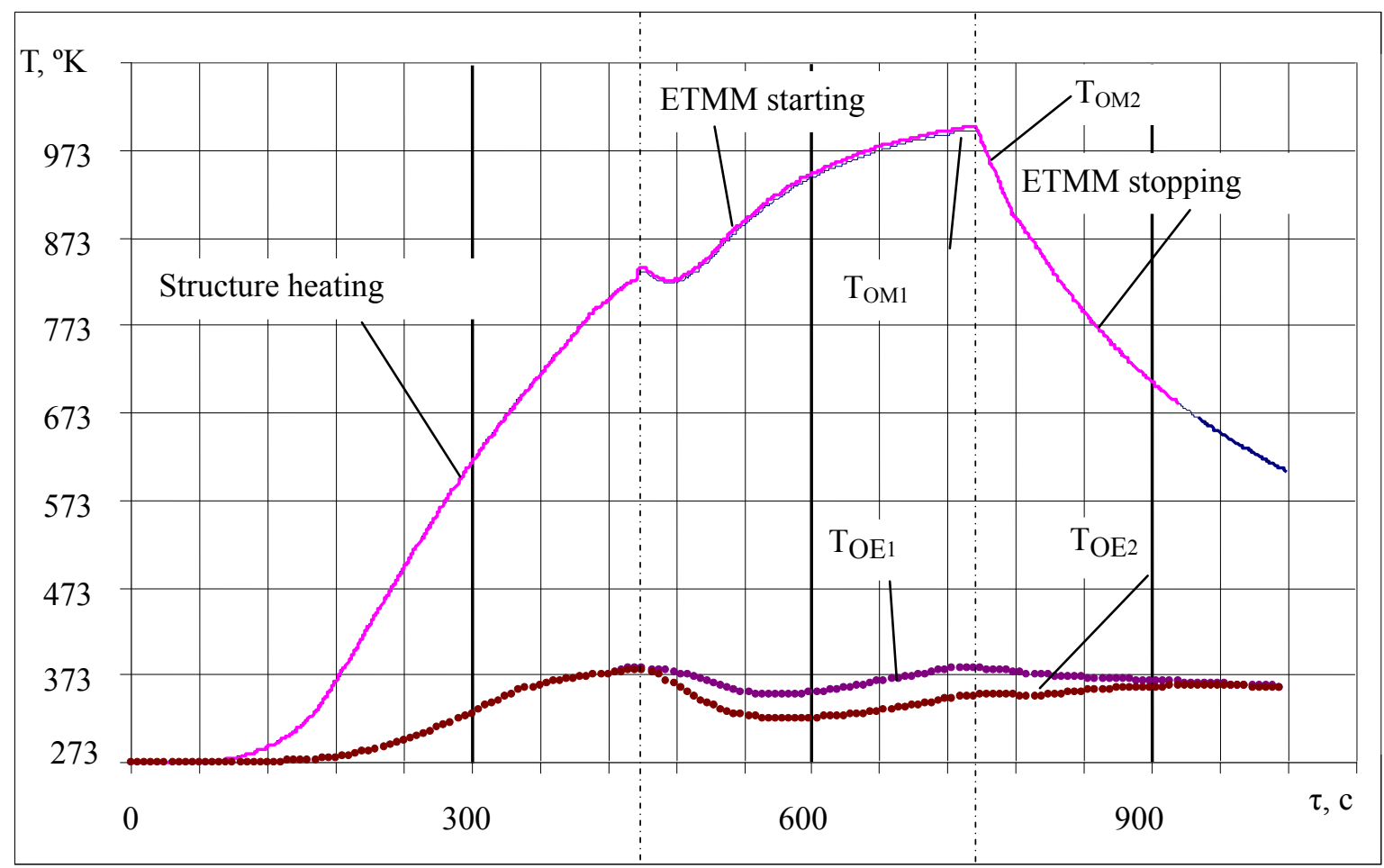

Figure 16. Ammonia temperature change in ETMM and evaporator casing temperature change at ETMM hot starting and its operation for $300 \mathrm{~s}$ at power consumption $60 \mathrm{~W}$ and gas-flow rate $\approx 12-16 \mathrm{mg} / \mathrm{s}$

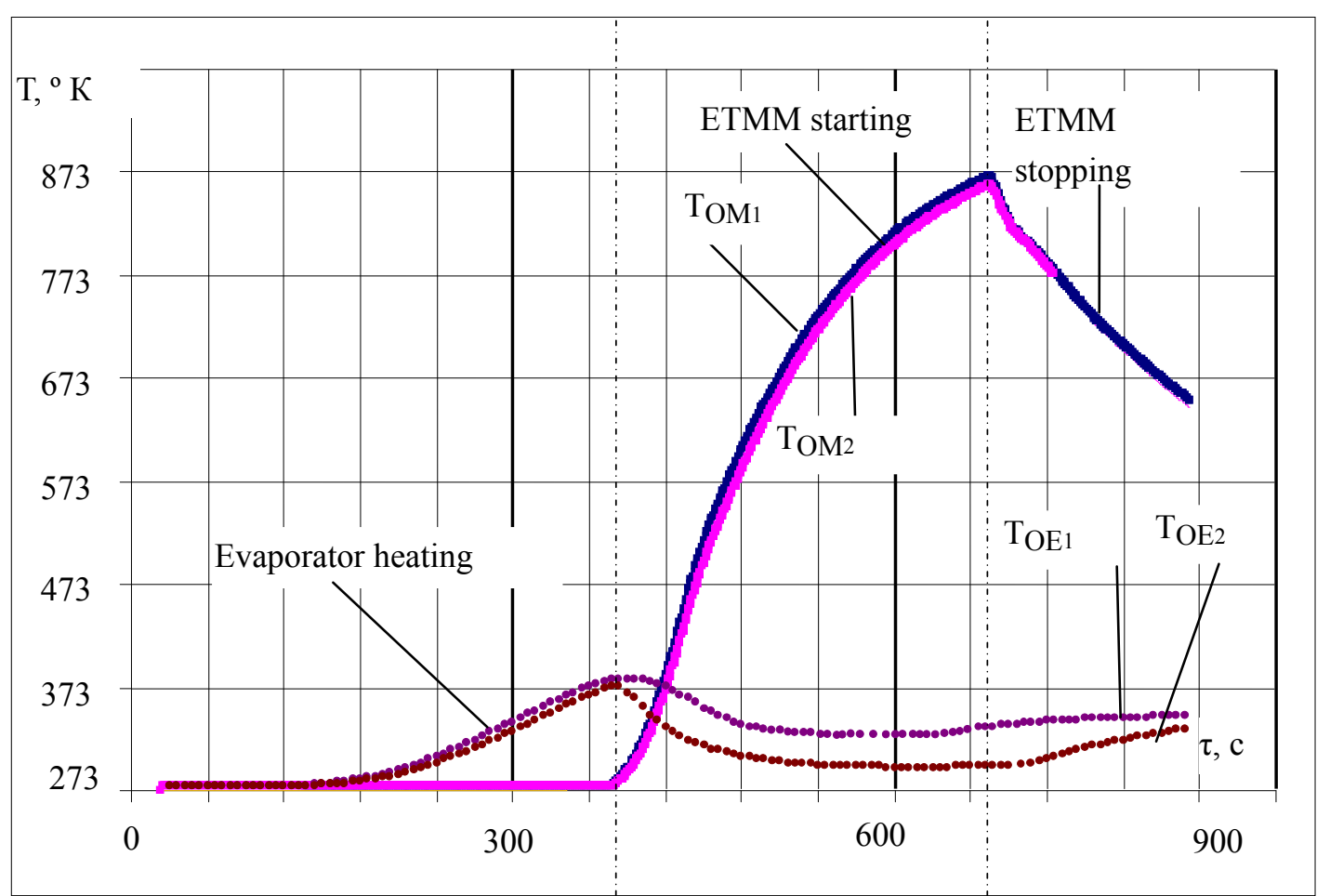

Figure 17. Ammonia temperature change in ETMM and evaporator casing temperature change at ETMM cold starting and its operation for $300 \mathrm{~s}$ at power consumption $60 \mathrm{~W}$ and gas-flow rate $\approx 12-16 \mathrm{mg} / \mathrm{s}$ 


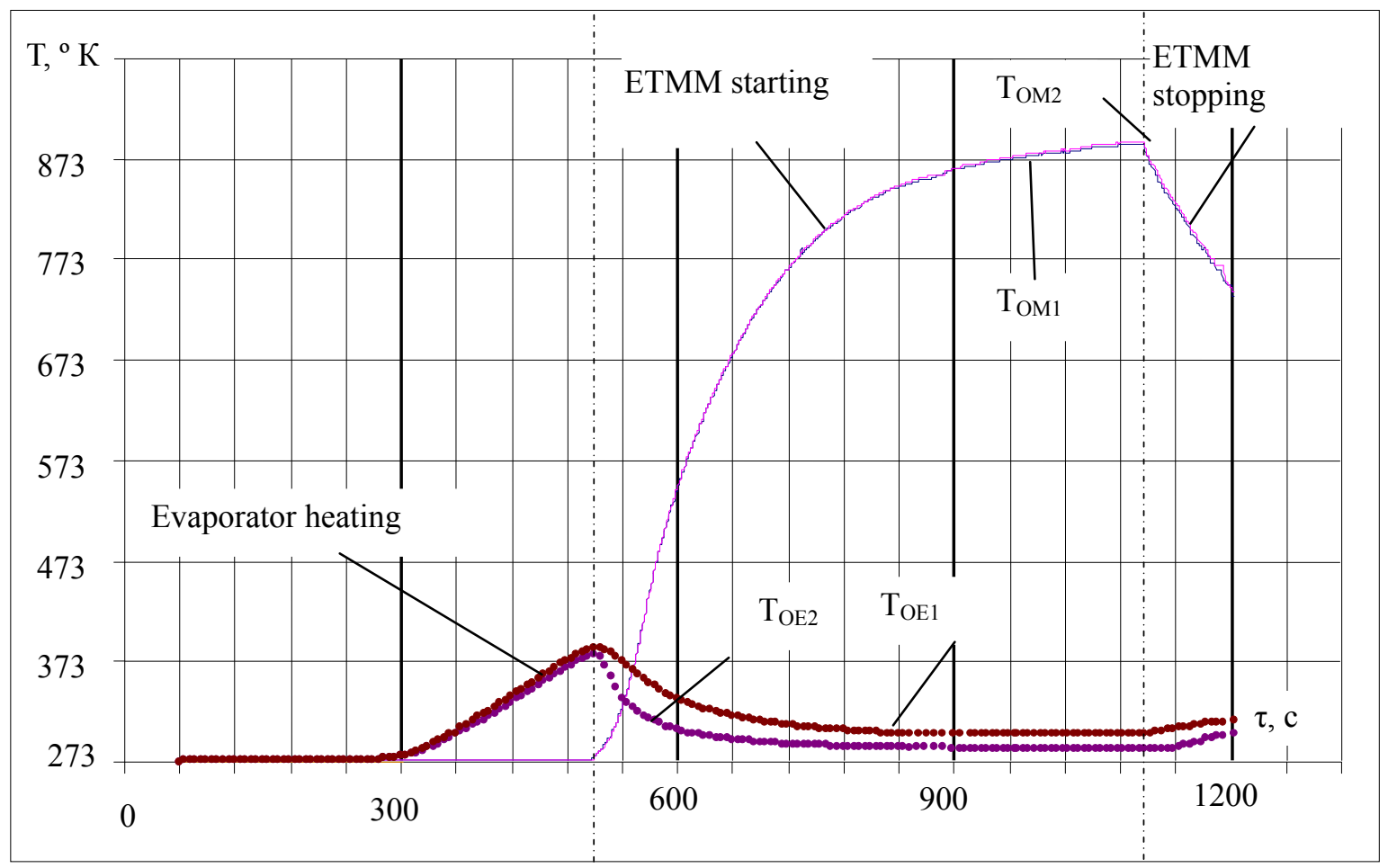

Figure 18. Ammonia temperature change in ETMM and evaporator casing temperature change at ETMM cold starting and its operation for $600 \mathrm{~s}$ at power consumption $60 \mathrm{~W}$ and gas-flow rate $\approx 12-16 \mathrm{mg} / \mathrm{s}$

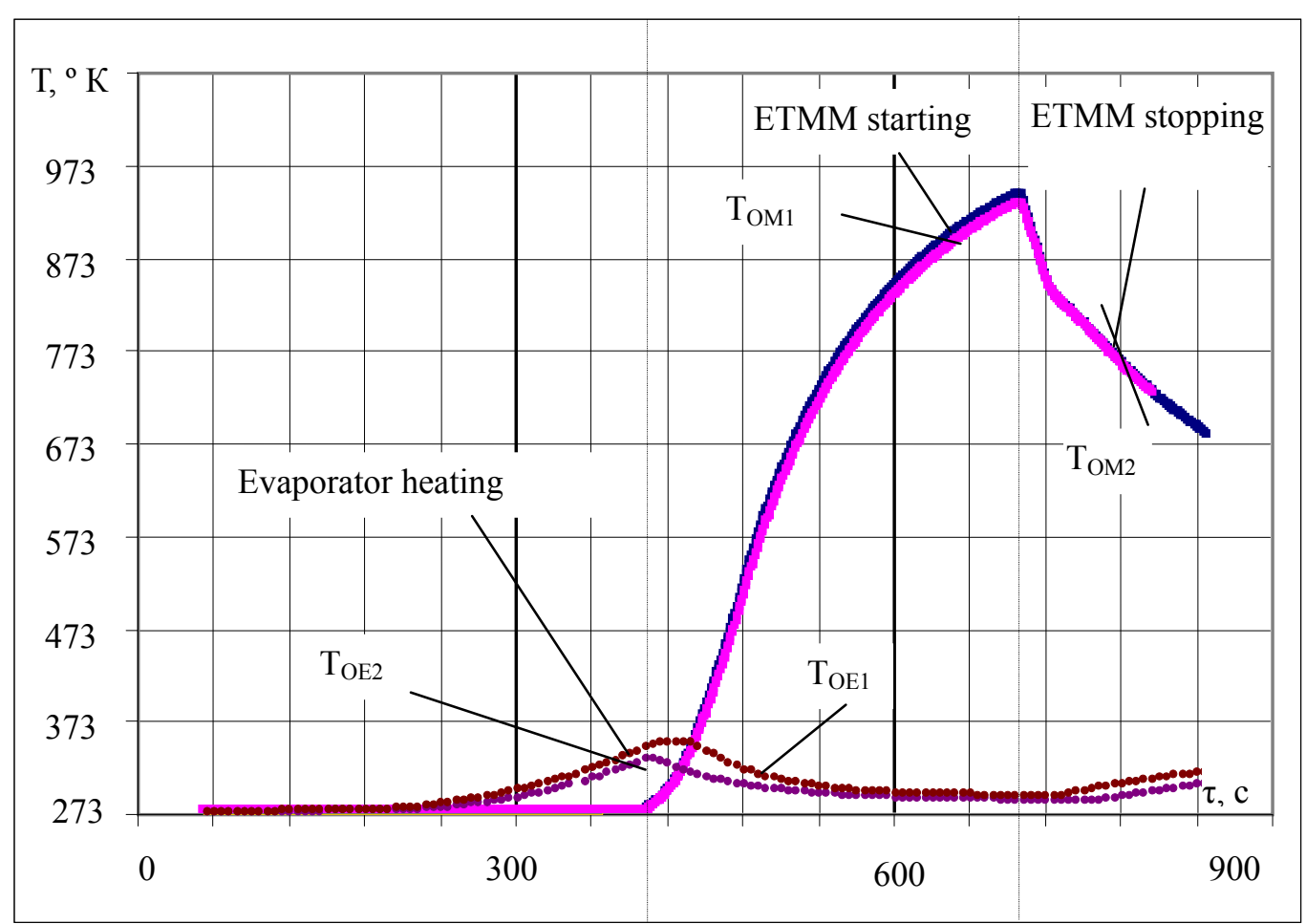

Figure 19. Ammonia temperature change in ETMM and evaporator casing temperature change at ETMM cold starting and its operation for $300 \mathrm{~s}$ at power consumption $80 \mathrm{~W}$ and gas-flow rate $\approx 12-16 \mathrm{mg} / \mathrm{s}$

To analyse the specialty areas of ammoniac CEU with ETMM in accordance with figure 12 using dimensions and mass equations (1-13) mass characteristics of CEU and its adaptation means to SSV are shown in Figure 20. 


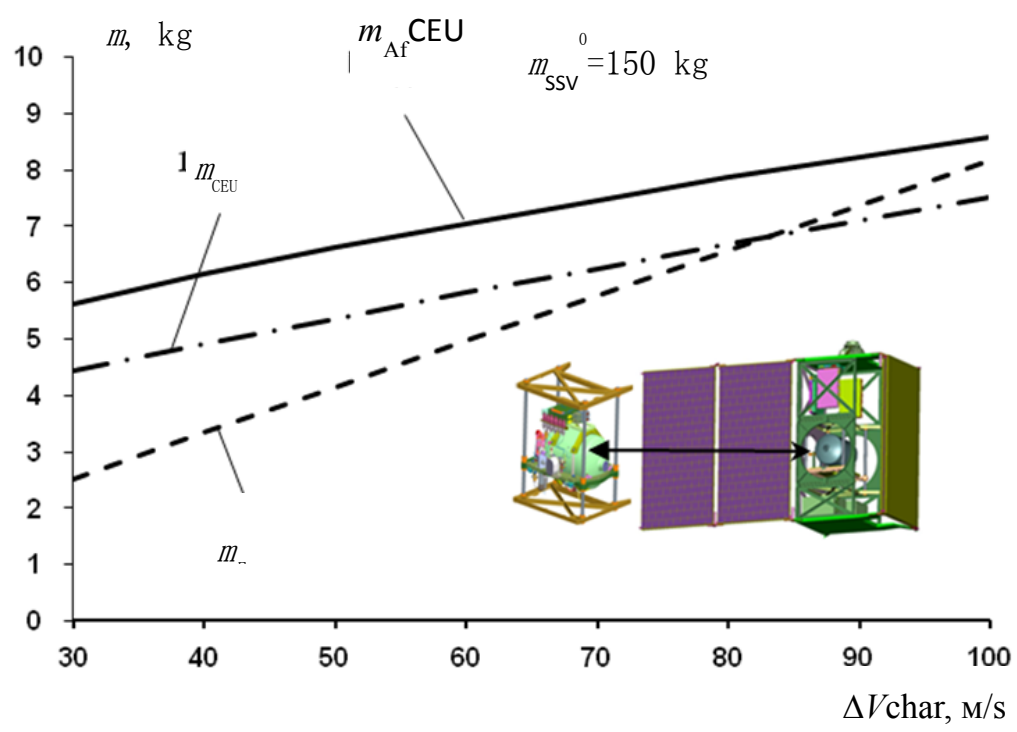

Figure 20. Change of dry mass of dislocating CEU to SSV, fuel, and CEU adaptation means to SSV with a mass of $150 \mathrm{~kg}$ depending on realizable reference speed

Reference speed through CEU and SSV parameters is defined according to the proportion:

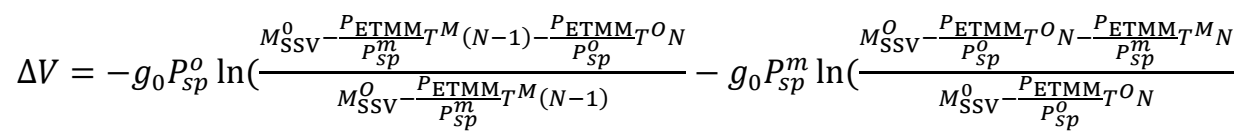

where $\Delta \mathrm{V}$ - reference speed;

$P_{s p}^{O}$ - mean thrust performance index of ETMM at starting operation;

$P_{s p}^{m}$ - mean thrust performance index of ETMM after starting operation;

$M_{\mathrm{SSV}}^{O}-\mathrm{SSV}$ throw mass;

$\mathrm{P}_{\mathrm{ETMM}}$ - ETMM thrust;

$\mathrm{T}^{\mathrm{O}}$ - ETMM retention time to starting operation;

$\mathrm{T}^{\mathrm{M}}$ - ETMM retention time at starting operation;

$\mathrm{N}$ - number of CEU starts.

The analysis of similar findings for SSV with a mass of 100-400 kg shows that for the realization of reference speed $100 \mathrm{~m} / \mathrm{s}$ the use of ammoniac CEU with ETMM with general energy consumption no more than $100 \mathrm{~W}$ as a part of SSV requires (19-12)\% of mass costs (fuel mass, CEU, CEU adaptation means to SSV - Figure 21). 


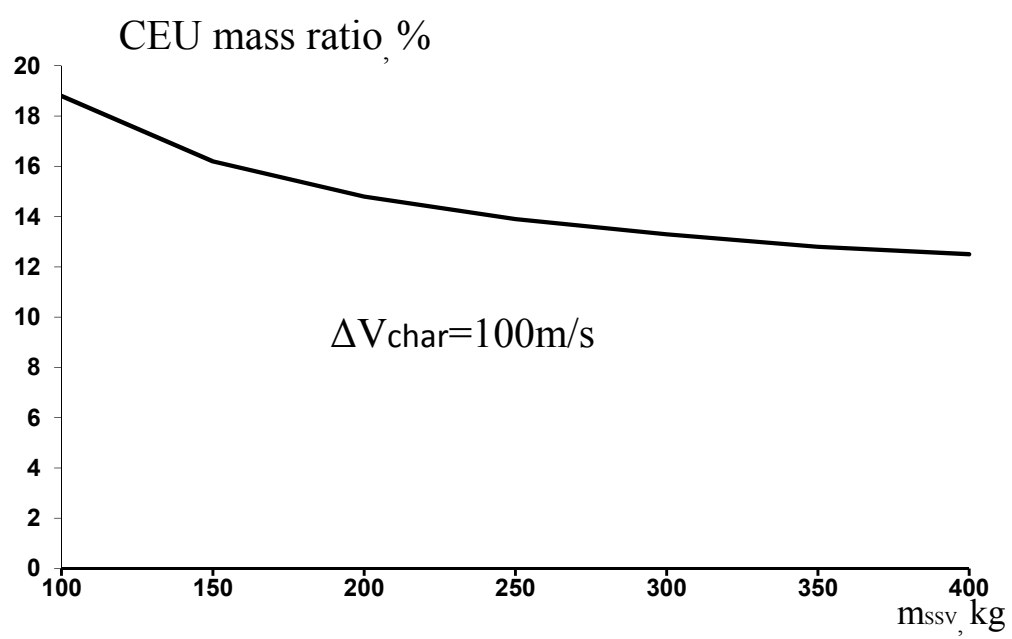

Figure 21. Mass ratio of CEU as a part of SSV

\section{Conclusions}

1. Low watt ammoniac CEU with ETMM with low value of thrust (to $4 \mathrm{~W} / \mathrm{MN}$ ) can be effectively used to solve SSV orbital manoeuvring tasks at a reference speed to $100 \mathrm{~m} / \mathrm{s}$.

2. Energy consumption operational range of developed ammoniac CEU with ETMM for SSV is 30-100W, which makes them usable for manoeuvrable SSV over a wide range of mass.

3. CEU construction method based on base and component structures of CEU, ETMM allows developing CEU and ETMM with reconfigurable and extensible structure producing quasioptimal design structural parameters of CEU as a part of EMTT.

4. High reliability of ammoniac CEU with ETMM is provided by pneumo- hydraulic scheme, control units, ETMM heating elements redundancy, and by cold starting use.

\section{References}

Blinov, V. N., \& Shalay, V. V. et al. (2014). The researches of correcting power units electro-thermal micromotors of manoeuvrable small space vehicles: monography. Ministry of Education and Science of the Russian Federation, OmSTU. Omsk: OmSTU Press, 264 p.: ill.

Blinov, V. N., Shalay, V. V., Hodoreva, E. V., \& Charushina, E. B. (2012). The Assessment of the Mass Effectiveness of Manoeuvrable Small Space Vehicles with Microdrive Power Unit on Ammonia. Omsk Scientific Herald, 1-107, 59-61.

Blinov, V. N. (2014). Experimental studies of the processes of rapid high temperature dissociating of ammonia when flowing through the limited volume in vacuum. Thermal processes in equipment, 1, 24-29.

Blinov, V. N., Charushina, E. B., \& Shalay, V. V. (2011). On the question of estimation of electrical micromotor power units use efficiency for small space vehicles orbital manoeuvring problem solving (pp. 39-45). Proceedings of the $6^{\text {th }}$ All-Russia scientific and technical conference, Omsk.

Blinov, V. N., Shalay, V. V., \& Hodoreva, E. V. (2012). The selection and use peculiarities of all-purpose methods of manoeuvrable small space vehicles designing. Systems, mechanisms and machines dynamics: Proceedings of the $8^{\text {th }}$ international scientific and technical conference, book 2, Omsk, 138-143.

Brusov, V. S., \& Baranov, S. K. (1989). Flight vehicles design optimization. All-purpose access. Moscow: Mashinostroenie.

Patent 2332583 FR, IPC7 F 02 K 9/68. Electro-thermal micromotor.Blinov, V. N., Ruban, V. I. [et al.]; No. 2000131736; pending 13.02.07; published 27.08.08., bulletin No. 24, 5 p.: ill.

Patent 2442011 RF, IPC F 02 K 9/68. Electro-thermal micromotor.Blinov, V. N., Ruban V. I. [et al.]; No. 2010127372; pending 02.07.10; published 10.02.12., bulletin No. 4. -12 p.: ill. 
Patent No. 2375267 RF, IPC B 64 G 1/10, B 64 G 1/22. All-purpose service platform for space vehicle development. Blinov, V. N., Ivanov N. N. [et al.]; No.2008124844/11; pending 17.06.2008; published 10.12.09., bulletin No. 34 .

Patent No.2457157 RF, IPC B64G1/10. Microsatellite for Earth remote probing. Abalihin, O. Y., Blinov, V. N. [et al.]; No. 2010149659; pending as of 07.12.2010; published 27.07.2012., bulletin No. 3 .

Sadovnichy, V. A., Bobrovnikov, S. Y., Aleksandrov, V. V., Lemak, S. S., Panasyuk, M. I., Yashin, I. V., ... Blinov, V. N. et al. (2011). Investigations of the Space Environment Aboard the Universitetsky-Tat'yana and Universitetsky-Tat'yana-2 Microsatellites. Solar System Research, 45(1), 3-29. http://dx.doi.org/10.1134/S0038094611010096

Sadovnichy, V. A., Panasyuk, M. I., Bobrovnikov, S. Yu., Vedenkin, N. N., Vlasova, N. A., Garipov, G. K., ... Blinov, V. N. et al. (2007). First Results of Investigating the Space Environment Onboard the Universitetskii-Tatyana Satellite. Cosmic Research, 273-286. http://dx.doi.org/10.1134/S0010952507040016

Small space vehicles: in 3 books (2010). Book 2. Microsatellites: Resource Book. [Blinov, V. N. et al.], Omsk, 272.

Small space vehicles: in 3 books (2010). Book 3. Minisatellites. Unified space platforms for small space vehicles: Resource Book. [Blinov, V.N. et al.]. Omsk: OmSTU Press, 348 p.

Small space vehicles: in 3 books (2010). Book. 1. Picosatellites. Nanosatellite: Resource Book. [Blinov, V. N. et al.], Omsk, 212.

\section{Copyrights}

Copyright for this article is retained by the author(s), with first publication rights granted to the journal.

This is an open-access article distributed under the terms and conditions of the Creative Commons Attribution license (http://creativecommons.org/licenses/by/3.0/). 